\title{
Article \\ Modeling Reference Crop Evapotranspiration Using Support Vector Machine (SVM) and Extreme Learning Machine (ELM) in Region IV-A, Philippines
}

\author{
Allan T. Tejada, Jr. ${ }^{1, *}$, Victor B. Ella ${ }^{2, *} \mathbb{( \mathbb { C }}$, Rubenito M. Lampayan ${ }^{2}$ and Consorcia E. Reaño ${ }^{3}$ \\ 1 Interdisciplinary Studies Center for Water, School of Environmental Science and Management, \\ University of the Philippines Los Baños, Los Baños 4031, Philippines \\ 2 Land and Water Resources Engineering Division, Institute of Agricultural and Biosystems Engineering, \\ College of Engineering and Agro-Industrial Technology, University of the Philippines Los Baños, \\ Los Baños 4031, Philippines; rmlampayan@up.edu.ph \\ 3 Institute of Crop Science, College of Agriculture and Food Science, University of the Philippines Los Baños, \\ Los Baños 4031, Philippines; cereano@up.edu.ph \\ * Correspondence: attejada@up.edu.ph (A.T.T.J.); vbella@up.edu.ph (V.B.E.)
}

check for updates

Citation: Tejada, A.T., Jr.; Ella, V.B.; Lampayan, R.M.; Reaño, C.E. Modeling Reference Crop Evapotranspiration Using Support Vector Machine (SVM) and Extreme Learning Machine (ELM) in Region IV-A, Philippines. Water 2022, 14, 754. https://doi.org/10.3390/w14050754 Academic Editors: Zheng Duan and Babak Mohammadi

Received: 17 January 2022 Accepted: 24 February 2022 Published: 26 February 2022

Publisher's Note: MDPI stays neutral with regard to jurisdictional claims in published maps and institutional affiliations.

Copyright: (C) 2022 by the authors. Licensee MDPI, Basel, Switzerland. This article is an open access article distributed under the terms and conditions of the Creative Commons Attribution (CC BY) license (https:// creativecommons.org/licenses/by/ $4.0 /)$.

\begin{abstract}
The need for accurate estimates of reference crop evapotranspiration (ETo) is important in irrigation planning and design, irrigation scheduling, reservoir management among other applications. ETo can be accurately determined using the internationally accepted FAO Penman-Monteith (FAO-56 PM) equation. However, this requires numerous observed data, including solar radiation, air temperature, relative humidity, and wind speed, which in most cases are unavailable, particularly in developing countries such as the Philippines. This study developed models based on Support Vector Machines (SVMs) and Extreme Learning Machines (ELMs) for the estimation of daily ETo using different input combinations of meteorological data in Region IV-A, Philippines. The performance of machine learning models was compared with the different established alternative empirical models for ETo. The results show that the SVM and ELM models, with at least $T_{\max }, T_{\min }$, and $R_{s}$ as inputs, provide the best daily ETo estimates. The accuracy of machine learning models was also found to be superior compared to the empirical models given with same input requirements. In general, SVM and ELM models showed similar modeling performance, although the former showed lower run time than the latter.
\end{abstract}

Keywords: reference crop evapotranspiration; machine learning; ELM; SVM

\section{Introduction}

The simultaneous occurrence of, and the difficulty of separately measuring, evaporation and transpirations gives rise to the concept of evapotranspiration [1]. Both evaporation and transpiration are influenced by factors such as weather parameters, crop characteristics, management, and environmental factors. Due to the complexity of the concept, distinctions are made among reference crop evapotranspiration (ETo), crop evapotranspiration under standard conditions (ETc) and crop evapotranspiration under non-standard conditions (ETc-adj). The reference crop evapotranspiration, ETo, which is the focus of this study, refers to the evapotranspiration rate from a reference surface, defined as a hypothetical grass reference crop with a height of $0.12 \mathrm{~m}$, a fixed surface resistance of $70 \mathrm{~s} / \mathrm{m}$, and an albedo of 0.23 , which is actively growing, well-watered, and completely shades the ground [1]. The concept of ETo was introduced to study the evaporative demand of the atmosphere independently of crop type, crop development, and management practices.

ETo is one of the most important agrometeorological inputs in the estimation of the irrigation water requirements needed for irrigation system planning, design, and operation [2-4]. Based on the Philippine Agricultural Engineering Standards [3] on the 
Determination of Irrigation Water Requirements, the calculation of ETo is a preliminary step in estimating the crop water requirements for the development of climate- and site-specific cropping calendars. Knowledge of ETo is also needed in the development of hydrologic models for streamflow estimation and flood inundation [5-7], reservoir design and operation [8,9], climate change studies [10-12], and drought severity analyses [13,14]. Hence, the importance of accurate methods for estimating ETo can never be overemphasized.

In general, ETo can be directly measured using the simple water balance derived from equipment such as a lysimeter. However, this method is extensive, labor-intensive, and time-consuming for practical applications [15]. In most cases, ETo is determined using the internationally accepted FAO Penman-Monteith (FAO-56 PM) equation [1]. Since FAO-56 PM requires numerous items of measured meteorological data that are mostly unavailable in developing countries such as the Philippines, empirical equations with reduced data requirements are usually utilized [16]. These equations are usually based on individual or combinations of available meteorological data, such as the temperature-based Hargreaves-Samani [17] equation, the temperature-radiation-based Makkink [18] and Priestley-Taylor [19] equations, the temperature-radiation and wind speed-based MattShuttleworth [20] equation, and the temperature-radiation and relative humidity-based Turc [21] equation. Although these empirical models are simple in terms of data inputs and computational procedures, their usage is observed to be site-specific, or variable according to the climatic conditions of the places where they are developed, and in some cases, they provide unsatisfactory results [22-24]. Furthermore, these simplified empirical models are mostly suited to estimating ETo on a weekly or monthly basis, but are less suitable for daily ETo estimation [25].

Advances in computation have led to the introduction of machine learning algorithms in accurate daily ETo estimation. The term machine learning was coined and first defined in a study on the International Business Machines (IBM) corporation as a field of study that gives computers the ability to learn without being explicitly programmed [26]. The popularity of machine learning in recent years can be attributed to the incorporation of probability and statistics into the algorithm that deals with traditional fixed rule-based models, which require manual input [27]. Machine learning models, in general, are black boxes in nature, but several studies conducted have shown their consistent reliability and accuracy in ETo estimation applications compared to other established empirical models [15,22,23,28-30]. Among these machine learning models, the Support Vector Machine (SVM) and Extreme Learning Machine (ELM) have generally exhibited better prediction accuracy in ETo estimations in various studies worldwide, such as in India [31], China [32,33], and Spain [34]. The performance of machine learning models relies on the proper estimation of hyperparameters [35], and cross-validations and resampling, along with grid search, are good ways to simultaneously optimize these hyperparameters [36,37]. The application of grid searches in machine learning model development for Eto estimation can be observed in the works of Bellido-Jiménez et al. [34], Seifi and Riahi [24], Patil and Deka [38], and Wen et al. [39].

Data-driven agricultural techniques, known collectively as precision agriculture, offer a potential way to increase global food production because of their more efficient and contextually appropriate agriculture management actions [40-42]. The recent expansion of data-driven farming is due to advances in three key areas: (1) data generation from sources such as field sensors and satellites, (2) data processing and predictive analytics using big data stacks, machine learning and deep learning models, and (3) human-computer interactions that create and improve the usability of insights and models [43]. Data-driven agricultural technologies mostly require the monitoring of accurate meteorological variables such as ETo [44]. For the past few decades, there has been an emerging trend of using machine learning models for the estimation of important variables, especially in areas where these data are insufficient, unavailable, or inaccessible [45].

To date, no study exists in the published peer-reviewed literature that explores the application of SVM and ELM models in the estimation of daily ETo under the conditions of the Philippines. The general objective of this study is to estimate daily ETo using SVM 
and ELM, with different input combinations of meteorological data collected at weather stations in Region IV-A, Philippines. Specifically, this study seeks to compare the accuracy of daily ETo estimation in the region (1) across the studied empirical models, (2) across machine learning models, i.e., across input combinations and between SVM and ELM, and (3) between the empirical models and machine learning models.

\section{Materials and Methods}

\subsection{Study Area}

Figure 1 shows the weather stations in Region IV-A, a region in the Philippines considered in this study. Twenty years of observed daily data on precipitation $(\mathrm{P}, \mathrm{mm})$, air temperature $\left(\mathrm{T}_{\max }\right.$ and $\left.\mathrm{T}_{\min },{ }^{\circ} \mathrm{C}\right)$, dew point temperature $\left(\mathrm{T}_{\mathrm{dew}},{ }^{\circ} \mathrm{C}\right)$, relative humidity $(\mathrm{RH}$, $\%)$ and wind speed $\left(\mathrm{U}_{\mathrm{z}}, \mathrm{m} / \mathrm{s}\right)$ were acquired from seven DOST-PAGASA weather stations in Region IV-A through the agency's online data acquisition platform ClimaDatPh. The requested data underwent a series of reliable quality control procedures and subsequent archiving, as described in the paper of Villafuerte et al. [46]. Based on the Modified Corona Climate Classification of the Philippines, the region can be divided into three zones: Type I, with a pronounced dry season from November to April, and wet during the rest of the year, which includes the stations in UPLB, Sangley Point, and Ambulong; Type III, with a relatively dry season from November to April, and wet during the rest of the year, which includes the station in Tanay; and lastly, Type IV is characterized with more or less even rainfall throughout the year, and it includes the stations in Infanta, Tayabas and Alabat. Table 1 shows the mean annual values of meteorological data per station.

Solar climatic variables in the region are scarce. Out of seven DOST-PAGASA stations in the region, only the UPLB station has available ground-based solar radiation data $\left(R_{S}\right.$, $\mathrm{MJ} / \mathrm{m}^{2}$ /day), with temporal records from 1977 to 2011 (35 years). For this reason, daily $\mathrm{R}_{\mathrm{s}}$ data from the Goddard Earth Observing System (GEOS) reanalysis datasets that can be accessed through the National Aeronautics and Space Administration Prediction of Worldwide Energy Resource (NASA POWER) website were used, given their relative consistency with the $R_{s}$ ground observations in the region [47]. Numerous publications have also proven the consistency of NASA-POWER $R_{S}$ values with the ground observations in many areas around the world [48-51].

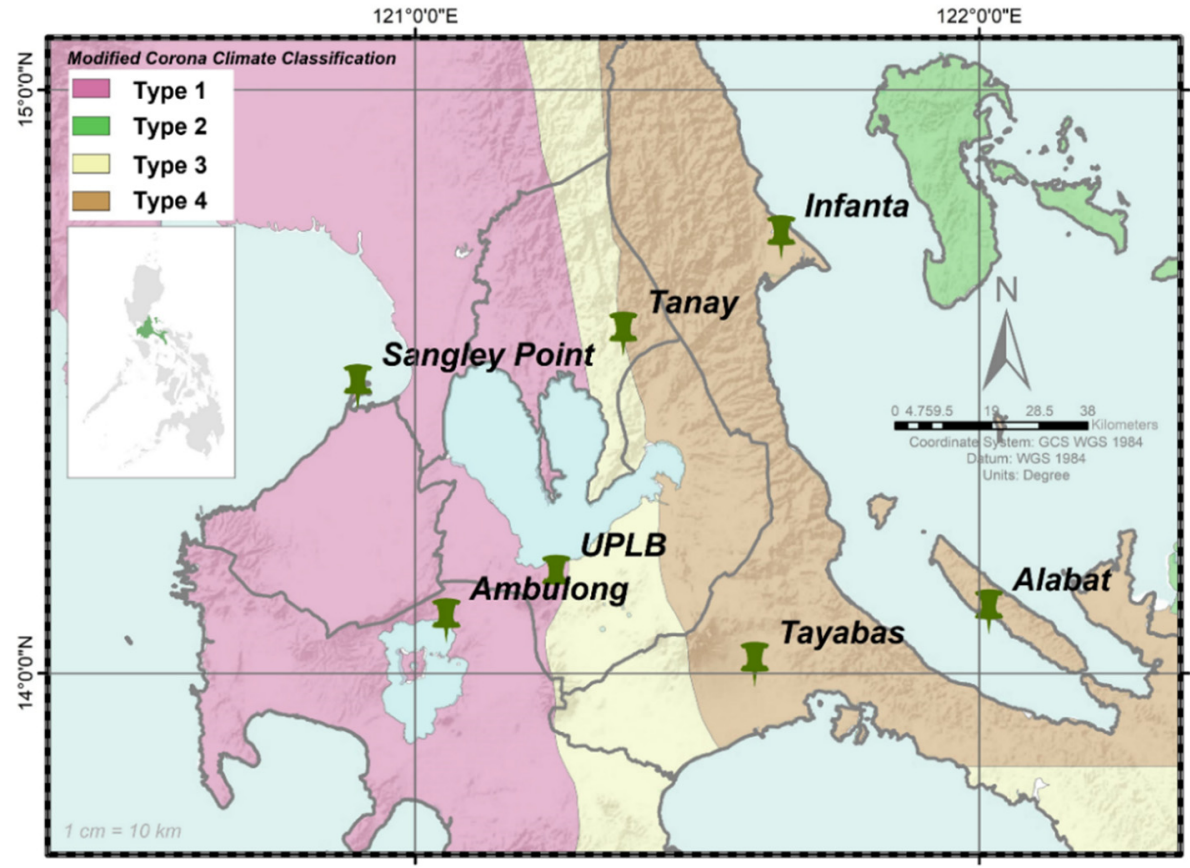

Figure 1. DOST-PAGASA weather stations considered in this study. 
Table 1. Temporal coverage of records and annual mean values of meteorological data of seven stations in Region IV-A.

\begin{tabular}{ccccccccccc}
\hline \multirow{2}{*}{ Province } & \multirow{2}{*}{ Station } & \multirow{2}{*}{ MASL } & \multicolumn{4}{c}{ Meterological Variable } & \multicolumn{4}{c}{ Temporal Range } \\
\cline { 5 - 11 } & & & $\mathbf{P}$ & $\mathbf{T}_{\mathbf{m a x}}$ & $\mathbf{T}_{\mathbf{m i n}}$ & $\mathbf{T}_{\mathbf{d e w}}$ & $\mathbf{R H}$ & $\mathbf{U}_{\mathbf{z}}$ & Devt & Eval \\
\hline \multirow{2}{*}{ Laguna } & UPLB & 25 & 2069 & 31.91 & 25.54 & 24.58 & 80.53 & 2.8 & $1995-2009$ & $2015-2019$ \\
\hline \multirow{2}{*}{ Cavite } & SangleyPoint & 3 & 2089 & 31.83 & 23.12 & 23.84 & 81.63 & 0.94 & $1984-1998$ & $1999-2003$ \\
\cline { 2 - 11 } & Infanta & 7 & 4171 & 30.58 & 23.63 & 23.79 & 84.35 & 2.01 & $1989-2003$ & $2010-2014$ \\
\hline \multirow{2}{*}{ Quezon } & Alabat & 5 & 3117 & 30.81 & 23.12 & 24.05 & 84.03 & 2.91 & $1992-2006$ & $2012-2016$ \\
\cline { 2 - 11 } & Tayabas & 158 & 3113 & 30.14 & 23.02 & 23.24 & 85.29 & 1.87 & $1994-2008$ & $2015-2019$ \\
\hline Batangas & Ambulong & 11 & 1845 & 31.89 & 23.32 & 23.39 & 79.94 & 1.79 & $1987-2001$ & $2015-2019$ \\
\hline Rizal & Tanay & 650 & 3014 & 30.10 & 23.23 & 20.92 & 89.47 & 3.37 & $2000-2014$ & $2015-2019$ \\
\hline
\end{tabular}

Units: MASL (meters above sea level)—m, P (precipitation)—mm/year, $\mathrm{T}$ (temperature)— ${ }^{\circ} \mathrm{C}, \mathrm{RH}$ (relative humidity)—\%, $\mathrm{U}_{\mathrm{z}}$ (wind Speed)—m/s. Notes: Devt—model development, Eval—model evaluation.

The datasets of each station were partitioned into two categories: (1) model development set for the development of machine learning models, and (2) model evaluation set for outsampled validation of the calibrated and developed models. A continuous 15 years daily record $(n \sim 5475)$ was used as the model development set, and a 5 years daily record ( $n \sim 1825)$ as the model evaluation set (Table 1).

\subsection{Empirical Models for ETo Estimation}

The daily ETo (mm/day), estimated using FAO-56 PM (Equation (1)), was used as the standard and reference value for the development and evaluation of the studied models.

$$
\mathrm{ETo}=\frac{0.408 \Delta\left(R_{n}-G\right)+\gamma \frac{900}{T+273} U_{2}\left(e_{s}-e_{a}\right)}{\Delta+\gamma\left(1+0.34 U_{2}\right)}
$$

in which $R_{n}$ is the net solar radiation (MJ $/ \mathrm{m}^{2}$-day), $G$ is the soil heat flux density ( $\mathrm{MJ} / \mathrm{m}^{2} /$ day), $T$ is the mean air temperature $\left({ }^{\circ} \mathrm{C}\right), U_{2}$ is the wind speed at $2 \mathrm{~m}$ height $(\mathrm{m} / \mathrm{s})$ converted from the wind speed measurement at $10 \mathrm{~m}$ height $\left(U_{10}\right)$ using a logarithmic wind speed profile [1], $e_{s}$ is the saturation vapor pressure $(\mathrm{kPA}), e_{a}$ is the actual vapor pressure $(\mathrm{kPa})$, $\Delta$ is the slope of the vapor pressure curve $\left(\mathrm{kPa} /{ }^{\circ} \mathrm{C}\right)$, and $\gamma$ is the psychometric constant $\left(\mathrm{kPa} /{ }^{\circ} \mathrm{C}\right)$. The detailed procedures and the theory for calculation are discussed in the FAO 56 paper [1].

Five alternative empirical equations that have respective meteorological data inputs, as shown in Table 2, were also employed to compute ETo per station. Detailed descriptions of each of these empirical models can be found in the paper of Guo et al. [52].

Table 2. Empirical equations for reference evapotranspiration estimation.

\begin{tabular}{cc}
\hline ETo Model & Equation \\
\hline & Temperature-based (T-based) \\
\hline Hargreaves-Samani [17] & ETo $=0.0135 C_{H S} \frac{R_{a}}{\lambda}(\Delta T)^{0.5} *\left(T_{\text {ave }}+17.8\right)$ \\
\hline Temperature and Solar Radiation-based (TS-based) \\
\hline Makkink [18] & ETo $=0.061\left(\frac{\Delta}{\Delta+\gamma} \frac{R_{s}}{2.45}\right)-0.12$ \\
\hline Priestley-Taylor [19] & ETo $=\alpha_{P T}\left(\frac{\Delta}{\Delta+\gamma} \frac{R_{a}}{\lambda}-\frac{G}{\lambda}\right)$ \\
\hline
\end{tabular}


Table 2. Cont.

\begin{tabular}{cc}
\hline ETo Model & Equation \\
\hline Temperature, Solar Radiation and Wind Speed-based (TSW-based) \\
\hline Matt-Shuttleworth [20] $\quad$ ETo $=\frac{1}{\lambda} \frac{\Delta R_{a}+\gamma \frac{\rho_{a c a} u_{2}\left(V P D_{2}\right)}{r_{c}^{50}}\left(\frac{V P D_{50}}{V P D_{2}}\right)}{\Delta+\gamma\left(1+\frac{\left(r_{s}\right)_{c} u_{2}}{r_{c}^{50}}\right)}$ \\
\hline Temperature, Solar Radiation and Relative Humidity-based (TSR-based) \\
\hline Turc [21] ETo $=0.013\left(23.88 R_{S}+50\right)\left(\frac{T_{a v e}}{T_{a v e}+15}\right)+\left(1+\frac{50-R H}{70}\right)$ \\
\hline
\end{tabular}

\subsection{Machine Learning Models for ETo Estimation}

Figure 2 shows the general methodology of the development of SVM and ELM for the estimation of daily ETo using different available meteorological data as inputs.

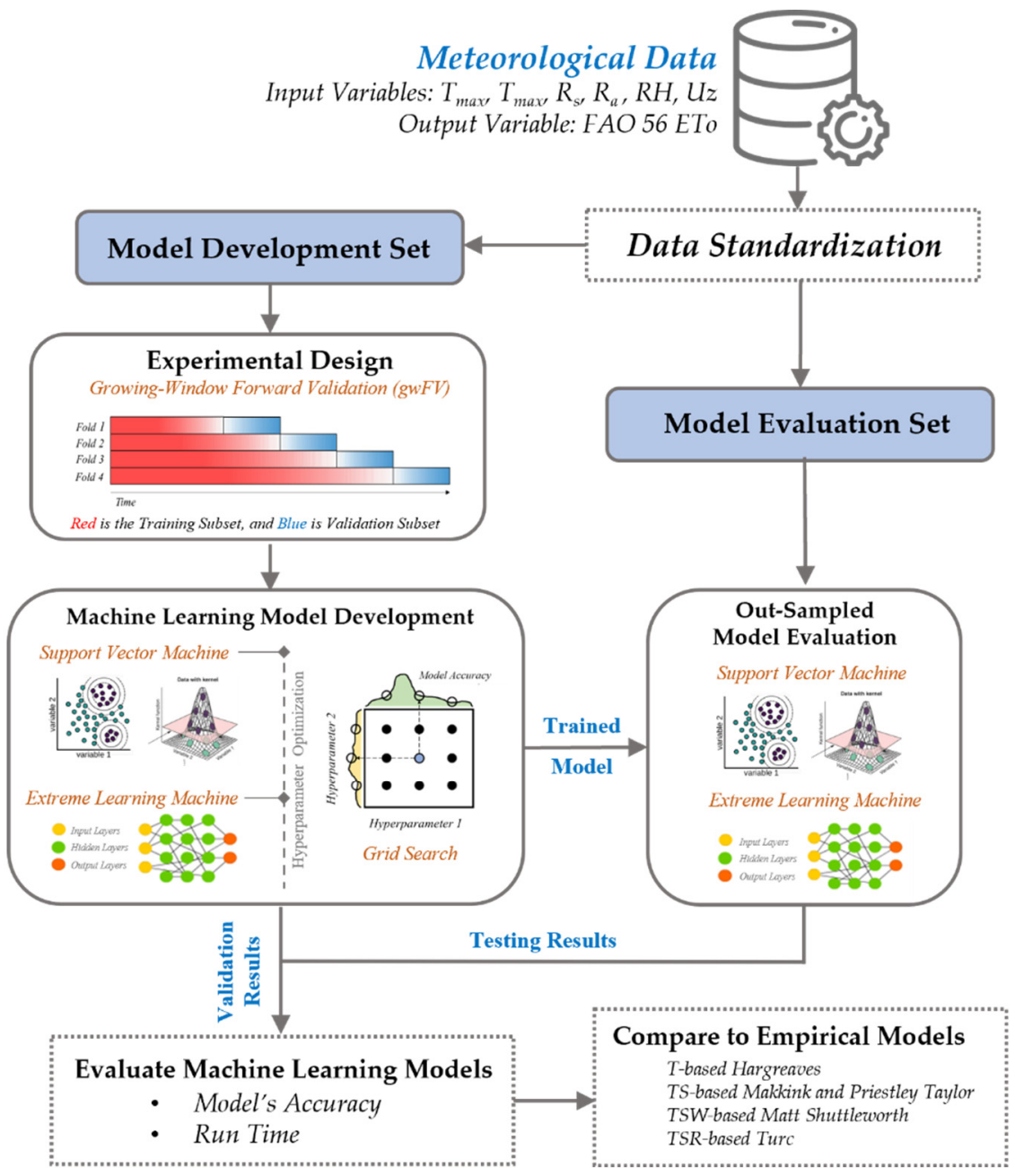

Figure 2. Methodology framework for developing SVM and ELM models for the estimation of daily ETo. Image Sources: Schematic Diagram of SVM (Rhys, 2020), ELM (van Veen and Leijnen, 2019), and grid search (Pilario et al., 2020).

\subsubsection{Support Vector Machine}

The SVM algorithm developed by Vapnik [53] is a supervised machine learning model for pattern recognition and data analysis, and it has been widely employed for regression and forecasting in the fields of agriculture, hydrology, meteorology, and environmental studies. The SVM model estimates the regression based on a series of kernel functions, 
which can convert the original, lower-dimensional input data to a higher dimensional feature space implicitly $[22,23]$. SVM works by transforming the input vector into a feature space and maps the relationship with the output vector. In general, the SVM can be expressed mathematically as:

$$
\mathrm{Y}=\mathrm{w} \varphi(\mathrm{X})+\mathrm{b}
$$

in which $\mathrm{Y}$ is the output vector, $\mathrm{w}$ is the weight vector, $\varphi$ is the kernel function, $\mathrm{X}$ is the input vector, and $b$ is the bias term. The weight factor $w$ and bias term $b$ are estimated by minimizing the loss function as:

$$
\begin{gathered}
0.5\|w\|^{2}+C \frac{1}{2} \sum_{i=1}^{n} L_{\epsilon}\left(y_{\text {predicted }}, y_{\text {actual }}\right) \\
L_{\epsilon}\left(y_{\text {predicted }}, y_{\text {actual }}\right)=f(x)=\left\{\begin{array}{r}
0, \text { if }\left|y_{\text {predicted }}-y_{\text {actual }}\right|<\varepsilon \\
\left|y_{\text {predicted }}-y_{\text {actual }}\right|-\varepsilon, \text { otherwise }
\end{array}\right.
\end{gathered}
$$

where the term $0.5\|w\|^{2}$ is the regularization term, $C$ is the penalty parameter, $L_{\epsilon}$ is the $\varepsilon$-insensitive error function, and $\varepsilon$ is the margin of SVM.

The transformation of the input vector is dictated by the kernel function, which adds an extra dimension to the SVM algorithm such that a linear hyperplane can separate the classes into new and higher-dimensional space [54]. There are different kernel functions that can be applied for the transformation of data suitable for finding linear decision boundaries for different non-linearly separable data sets. The commonly used Radial Basis Function (RBF) non-linear kernel function was used in this study due to its better performance in ETo and estimations compared with other kernel functions [22,29], which is expressed as:

$$
K\left(x_{n}, x_{i}\right)=\exp \left(-\gamma\left\|x_{n}-x_{i}\right\|^{2}+C\right)
$$

where $x_{n}$ and $x_{i}$ are the nth and ith terms of the input vector, while $\gamma$ and $C$ are the hyperparameters in the SVM- RDF model.

In this study, the hyperparameters $C$ and $\gamma$ were optimized simultaneously using a grid search method with $C$ ranging from 0.1 to 100 and $\varepsilon$ ranging from 0.001 to 10 , while a default value of 0.1 was used for the parameter $\varepsilon$. The grid search eliminates the trial-anderror method in tuning hyperparameters and has been proven to significantly improve the model's accuracy $[36,55]$.

\subsubsection{Extreme Learning Machine}

The ELM model proposed by Huang et al. [56] is an extended single hidden layer feedforward (FF) neural network wherein the weights and biases of the hidden layer are randomly generated without the need for tuning iteratively, while the output parameters are analytically calculated. ELM has a more favorable general capability with faster learning speed; it does not require too much human intervention and can run much faster than the conventional algorithms. ELM is an efficient algorithm with numerous advantages such as ease of use, quick learning speed, higher performance, and suitability for many nonlinear activation and kernel functions $[29,57,58]$. The basic theory of ELM can be given as follows:

For $\mathrm{M}$ arbitrary distinct inputs $\left(x_{i}, y_{i}\right)$ with $\in \mathbb{R}$ and $\in \mathbb{R}$, a standard single layer FF with $\mathcal{N}$ hidden nodes and the activation function $\mathfrak{f}$ can be modeled as the following sum:

$$
\sum_{\mathrm{i}=1}^{\mathcal{N}} \beta_{i} \mathfrak{f}\left(w_{i} x_{j}+b_{i}\right), j \in\{1,2,3, \ldots, M\}
$$


where $w_{i}$ is the input weights to the ith neuron in the hidden layer, $b_{i}$ are the biases, and $\beta_{i}$ is the output weights. In a case wherein a single-layer FF perfectly approximates the data, the relation is

$$
\sum_{i=1}^{\mathcal{N}} \beta_{i} \mathfrak{f}\left(w_{i} x_{j}+b_{i}\right)=y_{j}, j \in\{1,2,3, \ldots, M\}
$$

which can more efficiently be written as

$$
H \beta_{i}=Y
$$

where

$$
H=\left(\begin{array}{ccc}
\mathfrak{f}\left(w_{1} x_{1}+b_{1}\right) & \cdots & \mathfrak{f}\left(w_{n} x_{1}+b_{N}\right) \\
\vdots & \ddots & \vdots \\
\mathfrak{f}\left(w_{1} x_{M}+b_{1}\right) & \cdots & \mathfrak{f}\left(w_{N} x_{M}+b_{N}\right)
\end{array}\right)
$$

The hidden layer output matrix $H$ can be computed using the randomly generated first layer of the ELM and the training inputs, while the output weight $\beta$ can be solved by finding the least square solution to the linear system defined in the hidden layer output matrix $H$. This solution is given by $\beta=H^{\mathfrak{f}} Y$, where $H^{\mathfrak{f}}$ is the Moore-Penrose generalized inverse of the matrix $H$. The comprehensive derivation and description of the ELM algorithm can be found in the original paper of Huang et al. [56].

The kind of activation function (sigmoid, linear, or tansig) and the number of neurons in the hidden layer (ranging from 5 to 200 with an interval equal to 5 ) are the hyperparameters that were simultaneously tuned when using the grid search method.

\subsubsection{Machine Learning Model Development}

As shown in Table 3, eight different input combinations were considered to evaluate the effects of different meteorological variables on the estimation of daily ETo using machine learning models. Eight combinations of different input variables were considered for the SVM and ELM models. Model 1 has the same input combinations as the FAO-56 PM, namely, $T_{\max }, \mathrm{T}_{\min }, \mathrm{RH}, \mathrm{R}_{\mathrm{s}}$ and $\mathrm{U}_{\mathrm{z}}$. Model 2 has the same input combination as Model 1 , except that it uses extraterrestrial solar radiation $\left(R_{a}, M J / m^{2}\right.$-day) instead of $R_{s}$. Model 3 does not have any solar radiation variable, and uses only $T_{\max }, T_{\min }, R H$ and $U_{z}$. The input variables considered in Models 4, 5, and 6 are set to be analogous with the inputs of the TSR-, TSW-, and TS-based empirical equations, respectively. Model 7 only considers $\mathrm{T}_{\max }$ $\mathrm{T}_{\text {min, }}$ and RH. Finally, Model 8 only handles air temperature data, comparably with the T-based Hargreaves-Samani equation.

Table 3. The input combinations of meteorological variables used for the development of the SVM and ELM models for ETo estimation.

\begin{tabular}{ccc}
\hline \multirow{2}{*}{ Input Combinations } & \multicolumn{2}{c}{ Machine Learning Models } \\
\cline { 2 - 3 } & SVM & ELM \\
\hline $\mathrm{T}_{\max }, \mathrm{T}_{\min }, \mathrm{RH}, \mathrm{R}_{\mathrm{s}}, \mathrm{U}_{\mathrm{z}}$ & SVM ETo-Model 1 & ELM ETo-Model 1 \\
$\mathrm{T}_{\max }, \mathrm{T}_{\min }, \mathrm{RH}, \mathrm{R}_{\mathrm{a}}, \mathrm{U}_{\mathrm{z}}$ & SVM ETo-Model 2 & ELM ETo-Model 2 \\
$\mathrm{T}_{\max }, \mathrm{T}_{\min }, \mathrm{RH}, \mathrm{U}_{\mathrm{z}}$ & SVM ETo-Model 3 & ELM ETo-Model 3 \\
$\mathrm{T}_{\max }, \mathrm{T}_{\min }, \mathrm{RH}, \mathrm{R}_{\mathrm{s}}$ & SVM ETo-Model 4 & ELM ETo-Model 4 \\
$\mathrm{T}_{\max }, \mathrm{T}_{\min }, \mathrm{R}_{\mathrm{s}}, \mathrm{U}_{\mathrm{z}}$ & SVM ETo-Model 5 & ELM ETo-Model 5 \\
$\mathrm{T}_{\max }, \mathrm{T}_{\min }, \mathrm{R}_{\mathrm{s}}$ & SVM ETo-Model 6 & ELM ETo-Model 6 \\
$\mathrm{T}_{\max }, \mathrm{T}_{\min }, \mathrm{RH}$ & SVM ETo-Model 7 & ELM ETo-Model 7 \\
$\mathrm{T}_{\max }, \mathrm{T}_{\min }$ & SVM ETo-Model 8 & ELM ETo-Model 8 \\
\hline
\end{tabular}


In developing both SVM and ELM models, the model development set was further divided into a training subset and a validation subset for tuning the hyperparameters using a growing window-forward cross validation (gwFV) scheme. The gwFV is the recommended cross-validation scheme for machine learning models using time series data to preserve the temporal dependencies of the data, and provides almost unbiased estimates of the true error [59-61]. Four-folds gwFW were used for cross-validating the ETo model, a fixed window of 3 years $(n \sim 1095)$.

Before putting the input and output variables into the machine learning models, raw meteorological data were standardized to avoid convergence problems using the equation:

$$
X_{n}=\frac{X_{i}-\mu}{\sigma}
$$

where $X_{n}$ is the standardized value, $X_{i}$ is the measured value, $\mu$ is the mean, and $\sigma$ is the standard deviation. To reflect the real use of the models, the mean $(\mu)$ and standard deviation $(\sigma)$ were computed using only the data of the model development set.

\subsection{Evaluation of Model Performance}

\subsubsection{Model's Accuracy}

The accuracy and performance of both the empirical and machine learning models for ETo estimation were evaluated and compared using the statistical indicators shown in Table 4. To compare or rank the studied model considering all statistical indicators, the Global Performance Index (GPI) was computed:

$$
G P I_{i}=\sum_{j=1}^{j} \alpha_{j}\left(\widetilde{y}_{j}-y_{i j}\right)
$$

where $\widetilde{y}_{j}$ is the median of the scaled values of indicator $j, y_{i j}$ is the scaled value of indicator $j$ for model $I$, and $\alpha_{j}$ equals -1 for indicators $\mathrm{R}^{2}, \mathrm{~d}$ and NSE, and equals 1 for the other indicator.

Table 4. Statistical indicators used for the performance evaluation of machine learning and

\begin{tabular}{|c|c|c|}
\hline $\begin{array}{l}\text { Statistical } \\
\text { Indicator }\end{array}$ & Formula & Decision Rule \\
\hline Coefficient of Determination & $\mathrm{R}^{2}=\frac{\sum_{\mathrm{i}=1}^{\mathrm{n}}\left(\mathrm{X}_{\mathrm{i}}-\mathrm{Y}_{\mathrm{i}}\right)^{2}}{\sum_{\mathrm{i}=1}^{\mathrm{n}}\left(\mathrm{X}_{\mathrm{i}}-\overline{\mathrm{X}}\right)^{2}}$ & Higher values are preferred \\
\hline Root Mean Square Error & $\operatorname{RRMSE}=\sqrt{\frac{\sum_{\mathrm{i}=1}^{\mathrm{n}}\left(\mathrm{Y}_{\mathrm{i}}-\mathrm{X}_{\mathrm{i}}\right)^{2}}{\mathrm{n}}}$ & $\begin{array}{l}\text { Lower values are preferred } \\
\text { Shows performance of short-term models }\end{array}$ \\
\hline Relative RMSE & $\operatorname{RRMSE}=\left(\sqrt{\frac{\sum_{\mathrm{i}=1}^{\mathrm{n}}\left(\mathrm{Y}_{\mathrm{i}}-\mathrm{X}_{\mathrm{i}}\right)^{2}}{\overline{\mathrm{X}}_{\mathrm{i}}}}\right) * 100$ & $\begin{array}{l}\text { Excellent: RRMSE }<10 \% \\
\text { Satisfactory: } 10 \% \leq \text { RRMSE }<20 \% \\
\text { Acceptable: } 20 \% \leq \text { RRMSE }<30 \% \\
\text { Unsatisfactory: RRMSE } \geq 30\end{array}$ \\
\hline Percent Bias & $\%$ Bias $=\frac{1}{n} \sum_{i=1}^{n} \frac{X_{i}-Y_{i}}{X_{i}} * 100$ & Closer to 0 are preferred \\
\hline Mean Error & $\mathrm{ME}=\frac{\sum_{\mathrm{i}=1}^{\mathrm{n}}\left(\mathrm{Y}_{\mathrm{i}}-\mathrm{X}_{\mathrm{i}}\right)}{\mathrm{n}}$ & $\begin{array}{l}\text { Closer to } 0 \text { are preferred } \\
\text { Shows performance of long-term models }\end{array}$ \\
\hline $\begin{array}{l}\text { Mean Absolute } \\
\text { Error }\end{array}$ & MAE $=\frac{\sum_{i=1}^{n}\left|Y_{i}-X_{i}\right|}{n}$ & Lower values are preferred \\
\hline d Willmott & $\mathrm{d}=1-\left(\frac{\sum_{\mathrm{i}=1}^{\mathrm{n}}\left(\mathrm{Y}_{\mathrm{i}}-\mathrm{X}_{\mathrm{i}}\right)^{2}}{\sum_{\mathrm{i}=1}^{\mathrm{n}}\left(\left|\mathrm{Y}_{\mathrm{i}}-\overline{\mathrm{X}}\right|+\left|\mathrm{X}_{\mathrm{i}}-\overline{\mathrm{X}}\right|\right)}\right)$ & Higher values are preferred \\
\hline
\end{tabular}
empirical models. 
Table 4. Cont.

\begin{tabular}{ccl}
\hline $\begin{array}{c}\text { Statistical } \\
\text { Indicator }\end{array}$ & Formula & \multicolumn{1}{c}{ Decision Rule } \\
\hline $\begin{array}{c}\text { Nash-Sutcliffe } \\
\text { efficiency }\end{array}$ & $\mathrm{NSE}=1-\left(\frac{\sum_{\mathrm{i}=1}^{\mathrm{n}}\left(\mathrm{Y}_{\mathrm{i}}-\mathrm{X}_{\mathrm{i}}\right)^{2}}{\sum_{\mathrm{i}=1}^{\mathrm{n}}\left(\mathrm{X}_{\mathrm{i}}-\overline{\mathrm{X}}\right)^{2}}\right)$ & $\begin{array}{l}\text { Excellent: } 0.8 \leq \mathrm{NSE}<1 \\
\text { Satisfactory: } 0.65 \leq \mathrm{NSE}<0.8 \\
\text { Acceptable: } 0.5 \leq \mathrm{NSE}<0.65 \\
\text { Unsatisfactory: NSE }<0.5\end{array}$ \\
\hline MAPE & $\mathrm{MAPE}=\frac{1}{\mathrm{n}} \sum_{\mathrm{i}=1}^{\mathrm{n}}\left|\frac{\mathrm{X}_{\mathrm{i}}-\mathrm{Y}_{\mathrm{i}}}{\mathrm{X}_{\mathrm{i}}}\right|$ & Lower values are preferred \\
\hline
\end{tabular}

Where $n$ is the number of observations, $X_{i}$ represents the FAO-56 ETo value, $\bar{X}$ is the mean of the FAO-56 ETo value, $Y_{i}$ is the estimated ETo value, and $\bar{Y}$ is the mean of the estimated ETo value.

The concept of GPI indicates that if the scaled value of the indicator is far lower than the median of the scaled values, the model is the most accurate compared to other models, while if the scaled value of indicator is far higher than the median, the model is less accurate compared to the other models [62]. A higher value of GPI results in a higher accuracy of the model.

\subsubsection{Machine Learning Model's Run Time}

The run time or the time used for the computation of the machine learning models across models and between SVM and ELM were also compared in this study using a single sample with 4-fold gwFV cross-validation.

\section{Results and Discussions}

Tables 5-11 show the results of statistical indicators for all studied models given by the stations at UPLB, Sangley Point, Infanta, Alabat, Tayabas, Ambulong, and Tanay. Additionally, the computed GPI values per model and stations are presented in Table 12.

\subsection{Comparison across Empirical Models}

Based on the different statistical indicators and the ranking of the computed GPI, the TSR-based Turc equation performs the best among the studied empirical models in the estimation of daily ETo for all stations, except in Tanay, where it ranked second after the Makkink equation. On average, the estimated daily ETo of the Turc equation is only 6.0 to $15.2 \%$ divergent from the standard FAO-56 PM daily ETo. This fits with an $\mathrm{R}^{2}$ of $0.93-0.97$, an RMSE of $0.28-0.46 \mathrm{~mm} /$ day, an RRMSE of 7.5-15.1\%, an MAE of $0.22-0.42 \mathrm{~mm} /$ day, and an NSE of 0.79-0.94. The Turc equation is best used in places where there are no wind speed data available. It is considered as one of the most accurate empirical models used to estimate ETo under humid conditions [29]. Nevertheless, the T-based Hargreaves equation gives the lowest accuracy across stations, with estimates that are $26.9-48.7 \%$ divergent from the standard FAO-56 PM ETo, with an $\mathrm{R}^{2}$ of 0.19-0.35, an RMSE of 1.02-1.25 mm/day, an RRMSE of 25.3-40.0\%, an MAE of $0.77-0.098 \mathrm{~mm} /$ day, and an NSE of $-0.46-0.27$.

The ranking of the investigated empirical models according to GPI is the same for the UPLB, Infanta, Alabat and Tayabas stations, i.e., Turc > Matt-Shuttleworth > Makkink $>$ Priestley-Taylor $>$ Hargreaves-Samani. The ranking shows that incorporating relative humidity (TSR-based) and wind speed (TSW-based), along with solar radiation and air temperature, could improve the estimates of empirical models. 
Table 5. Statistical values of empirical and machine learning models in estimating daily ETo at UPLB Station.

\begin{tabular}{|c|c|c|c|c|c|c|c|c|c|c|c|c|c|c|c|c|c|c|}
\hline \multirow{2}{*}{ MODEL } & \multicolumn{9}{|c|}{ Model Development } & \multicolumn{9}{|c|}{ Model Evaluation } \\
\hline & $\mathbf{R}^{2}$ & RMSE & RRMSE & $\%$ Bias & ME & MAE & $\mathrm{d}$ & NSE & MAPE & $\mathbf{R}^{2}$ & RMSE & RRMSE & $\%$ Bias & ME & MAE & d & NSE & MAPE \\
\hline Hargreaves-Samani & 0.28 & 1.19 & 30.318 & -26.7 & 0.46 & 0.93 & 0.62 & 0.15 & 35.335 & 0.28 & 1.06 & 26.236 & -17 & 0.3 & 0.86 & 0.61 & 0.2 & 27.327 \\
\hline Makkink & 0.95 & 0.67 & 17.036 & 17.6 & -0.61 & 0.61 & 0.94 & 0.73 & 17.677 & 0.97 & 0.51 & 12.684 & 12.6 & -0.47 & 0.47 & 0.95 & 0.81 & 12.664 \\
\hline Matt-Shuttleworth & 0.93 & 0.61 & 15.636 & 13 & -0.5 & 0.5 & 0.94 & 0.77 & 13.05 & 0.96 & 0.38 & 9.44 & 7.4 & -0.3 & 0.3 & 0.97 & 0.9 & 7.476 \\
\hline Turc & 0.95 & 0.32 & 8.151 & -3.4 & 0.14 & 0.25 & 0.99 & 0.94 & 7.162 & 0.97 & 0.36 & 8.779 & -7.5 & 0.29 & 0.31 & 0.98 & 0.91 & 8.313 \\
\hline SVM ETo Model 1 & 0.988 & 0.122 & 3.074 & 0 & -0.009 & 0.089 & 0.998 & 0.991 & 2.704 & 0.985 & 0.117 & 2.861 & -1.9 & -0.018 & 0.088 & 0.998 & 0.99 & 4.603 \\
\hline SVM ETo Model 2 & 0.711 & 0.679 & 17.071 & -4.9 & 0.03 & 0.524 & 0.916 & 0.723 & 15.868 & 0.664 & 0.749 & 18.384 & 5 & -0.471 & 0.611 & 0.882 & 0.602 & 19.833 \\
\hline SVM ETo Model 4 & 0.968 & 0.215 & 5.407 & 0 & -0.013 & 0.153 & 0.993 & 0.972 & 4.445 & 0.97 & 0.167 & 4.089 & -4.1 & 0.064 & 0.125 & 0.995 & 0.98 & 5.795 \\
\hline SVM ETo Model 5 & 0.985 & 0.135 & 3.393 & 0 & -0.01 & 0.097 & 0.997 & 0.989 & 2.962 & 0.983 & 0.129 & 3.157 & -1.9 & -0.016 & 0.093 & 0.997 & 0.988 & 4.633 \\
\hline SVM ETo Model 6 & 0.959 & 0.238 & 5.981 & 0.2 & -0.022 & 0.169 & 0.991 & 0.966 & 4.914 & 0.963 & 0.186 & 4.55 & -4.3 & 0.084 & 0.145 & 0.994 & 0.976 & 5.908 \\
\hline SVM ETo Model 7 & 0.611 & 0.784 & 19.695 & -5.5 & 0.012 & 0.62 & 0.879 & 0.631 & 18.475 & 0.647 & 0.724 & 17.753 & 1.5 & -0.365 & 0.586 & 0.886 & 0.629 & 19.89 \\
\hline SVM ETo Model 8 & 0.584 & 0.81 & 20.35 & -5.9 & 0.007 & 0.641 & 0.866 & 0.606 & 19.272 & 0.639 & 0.716 & 17.57 & -1.3 & -0.315 & 0.57 & 0.886 & 0.636 & 20.851 \\
\hline ELM ETo Model 1 & 0.99 & 0.121 & 3.032 & -0.2 & 0 & 0.086 & 0.998 & 0.991 & 2.616 & 0.99 & 0.114 & 2.787 & -1 & 0 & 0.082 & 0.998 & 0.991 & 3.2 \\
\hline ELM ETo Model 2 & 0.695 & 0.689 & 17.311 & -4.3 & 0 & 0.537 & 0.911 & 0.715 & 16.194 & 0.654 & 0.771 & 18.917 & 10.9 & -0.497 & 0.629 & 0.875 & 0.578 & 15.482 \\
\hline ELM ETo Model 3 & 0.685 & 0.701 & 17.604 & -4.5 & 0 & 0.549 & 0.908 & 0.705 & 16.582 & 0.65 & 0.778 & 19.085 & 8.6 & -0.503 & 0.636 & 0.873 & 0.571 & 17.469 \\
\hline ELM ETo Model 4 & 0.969 & 0.217 & 5.461 & -0.5 & 0 & 0.158 & 0.993 & 0.972 & 4.658 & 0.966 & 0.179 & 4.392 & -6.6 & 0.075 & 0.129 & 0.994 & 0.977 & 8.119 \\
\hline ELM ETo Model 6 & 0.963 & 0.237 & 5.96 & -0.7 & 0 & 0.173 & 0.991 & 0.966 & 5.173 & 0.958 & 0.198 & 4.862 & -6.6 & 0.105 & 0.155 & 0.993 & 0.972 & 7.912 \\
\hline ELM ETo Model 7 & 0.615 & 0.777 & 19.536 & -5.3 & 0 & 0.615 & 0.879 & 0.637 & 18.327 & 0.648 & 0.724 & 17.764 & 2.5 & -0.37 & 0.586 & 0.886 & 0.628 & 18.956 \\
\hline ELM ETo Model 8 & 0.578 & 0.815 & 20.47 & -5.6 & -0.003 & 0.646 & 0.864 & 0.601 & 19.409 & 0.64 & 0.717 & 17.575 & 1.9 & -0.318 & 0.575 & 0.886 & 0.636 & 17.993 \\
\hline
\end{tabular}

Notes: (1) Best statistical indicators among each category (Empirical Model, SVM, and ELM) are marked in bold green, while least accurate are marked in bold red.

(2) $\mathrm{R}^{2}$, d and NSE are dimensionless; RRMSE, \%Bias and MAPE are in percent; and RMSE, ME, and MAE are in mm/day.

(3) Highlight colors of models indicate the input or independent variables considered, i.e., 
Table 6. Statistical values of empirical and machine learning models used for estimating daily ETo at Sangley Point Station.

\begin{tabular}{|c|c|c|c|c|c|c|c|c|c|c|c|c|c|c|c|c|c|c|}
\hline \multirow{2}{*}{ MODEL } & \multicolumn{9}{|c|}{ Model Development } & \multicolumn{9}{|c|}{ Model Evaluation } \\
\hline & $\mathbf{R}^{2}$ & RMSE & RRMSE & $\%$ Bias & ME & MAE & d & NSE & MAPE & $\mathbf{R}^{2}$ & RMSE & RRMSE & $\%$ Bias & ME & MAE & d & NSE & MAPE \\
\hline Hargreaves-Samani & 0.19 & 1.25 & 28.627 & -21.4 & 0.16 & 0.93 & 0.54 & 0.17 & 34.921 & 0.25 & 1.11 & 25.19 & -15.6 & 0.18 & 0.84 & 0.61 & 0.22 & 27.561 \\
\hline Makkink & 0.94 & 0.88 & 20.185 & 20.3 & -0.81 & 0.81 & 0.89 & 0.59 & 20.292 & 0.93 & 1.08 & 24.46 & 24.4 & -1.02 & 1.02 & 0.83 & 0.27 & 24.397 \\
\hline Matt-Shuttleworth & 0.89 & 0.99 & 22.831 & 19.6 & -0.86 & 0.86 & 0.86 & 0.47 & 19.597 & 0.86 & 1.16 & 26.205 & 23.7 & -1.05 & 1.05 & 0.79 & 0.16 & 23.68 \\
\hline Turc & 0.95 & 0.33 & 7.496 & 0.4 & -0.04 & 0.24 & 0.98 & 0.94 & 6.078 & 0.93 & 0.43 & 9.693 & 5.5 & -0.25 & 0.31 & 0.97 & 0.89 & 7.098 \\
\hline SVM ETo Model 1 & 0.99 & 0.086 & 1.966 & 0.4 & -0.025 & 0.075 & 0.999 & 0.996 & 1.93 & 0.988 & 0.088 & 1.987 & 0.6 & -0.031 & 0.074 & 0.999 & 0.995 & 1.805 \\
\hline SVM ETo Model 2 & 0.846 & 0.539 & 12.383 & -4.4 & 0.056 & 0.388 & 0.957 & 0.845 & 12.175 & 0.811 & 0.598 & 13.509 & -11.6 & 0.378 & 0.444 & 0.94 & 0.777 & 13.163 \\
\hline SVM ETo Model 4 & 0.985 & 0.158 & 3.641 & -0.1 & -0.004 & 0.117 & 0.997 & 0.987 & 2.956 & 0.963 & 0.22 & 4.978 & -1.1 & 0.045 & 0.164 & 0.993 & 0.97 & 3.907 \\
\hline SVM ETo Model 5 & 0.983 & 0.164 & 3.773 & -0.1 & -0.005 & 0.119 & 0.996 & 0.986 & 3.27 & 0.926 & 0.297 & 6.711 & 3.1 & -0.142 & 0.18 & 0.986 & 0.945 & 4.204 \\
\hline SVM ETo Model 6 & 0.961 & 0.241 & 5.534 & 0.1 & -0.023 & 0.173 & 0.992 & 0.969 & 4.399 & 0.905 & 0.349 & 7.88 & 2.9 & -0.14 & 0.239 & 0.98 & 0.924 & 5.434 \\
\hline SVM ETo Model 7 & 0.797 & 0.606 & 13.935 & -4.2 & 0.033 & 0.471 & 0.944 & 0.804 & 13.93 & 0.743 & 0.743 & 16.802 & -14.3 & 0.496 & 0.599 & 0.912 & 0.655 & 16.506 \\
\hline SVM ETo Model 8 & 0.668 & 0.773 & 17.782 & -7.5 & 0.041 & 0.594 & 0.896 & 0.681 & 18.826 & 0.664 & 0.75 & 16.958 & -8.1 & 0.181 & 0.588 & 0.897 & 0.649 & 16.532 \\
\hline ELM ETo Model 1 & 0.997 & 0.066 & 1.523 & 0 & 0 & 0.051 & 0.999 & 0.998 & 1.335 & 0.993 & 0.08 & 1.809 & 0.2 & -0.013 & 0.059 & 0.999 & 0.996 & 1.431 \\
\hline ELM ETo Model 2 & 0.835 & 0.535 & 12.307 & -3.2 & 0 & 0.395 & 0.957 & 0.847 & 12.209 & 0.822 & 0.567 & 12.826 & -10.7 & 0.341 & 0.425 & 0.946 & 0.799 & 12.608 \\
\hline ELM ETo Model 3 & 0.809 & 0.578 & 13.277 & -3.5 & 0 & 0.447 & 0.949 & 0.822 & 13.453 & 0.772 & 0.65 & 14.701 & -11.9 & 0.368 & 0.506 & 0.926 & 0.736 & 14.687 \\
\hline ELM ETo Model 4 & 0.986 & 0.157 & 3.614 & -0.2 & 0 & 0.117 & 0.997 & 0.987 & 2.954 & 0.961 & 0.237 & 5.362 & -0.8 & 0.029 & 0.168 & 0.991 & 0.965 & 3.951 \\
\hline ELM ETo Model 6 & 0.967 & 0.239 & 5.491 & -0.4 & 0 & 0.176 & 0.992 & 0.97 & 4.526 & 0.907 & 0.34 & 7.689 & 2.9 & -0.143 & 0.234 & 0.981 & 0.928 & 5.371 \\
\hline ELM ETo Model 7 & 0.789 & 0.608 & 13.979 & -3.7 & 0 & 0.475 & 0.943 & 0.803 & 14.058 & 0.72 & 0.758 & 17.125 & -13.8 & 0.462 & 0.594 & 0.907 & 0.642 & 16.487 \\
\hline ELM ETo Model 8 & 0.665 & 0.769 & 17.677 & -6.3 & 0 & 0.595 & 0.899 & 0.685 & 18.567 & 0.532 & 0.888 & 20.063 & -5.6 & 0.05 & 0.632 & 0.855 & 0.508 & 17.101 \\
\hline
\end{tabular}

Notes: (1) Best statistical indicators among each category (Empirical Model, SVM, and ELM) are marked in bold green, while least accurate are marked in bold red.

(2) $\mathrm{R}^{2}$, d and NSE are dimensionless; RRMSE, \%Bias and MAPE are in percent; and RMSE, ME, and MAE are in mm/day.

(3) Highlight colors of models indicate the input or independent variables considered, i.e., 
Table 7. Statistical values of empirical and machine learning models used for estimating daily ETo at Infanta Station.

\begin{tabular}{|c|c|c|c|c|c|c|c|c|c|c|c|c|c|c|c|c|c|c|}
\hline \multirow{2}{*}{ MODEL } & \multicolumn{9}{|c|}{ Model Development } & \multicolumn{9}{|c|}{ Model Evaluation } \\
\hline & $\mathbf{R}^{2}$ & RMSE & RRMSE & $\%$ Bias & ME & MAE & $\mathrm{d}$ & NSE & MAPE & $\mathbf{R}^{2}$ & RMSE & RRMSE & $\%$ Bias & ME & MAE & d & NSE & MAPE \\
\hline Hargreaves-Samani & 0.29 & 1.24 & 35.571 & -39.8 & 0.87 & 0.93 & 0.59 & -0.41 & 40.923 & 0.36 & 1.21 & 34.27 & -36.8 & 0.84 & 0.93 & 0.61 & -0.25 & 38.645 \\
\hline Makkink & 0.94 & 0.58 & 16.704 & 16.9 & -0.52 & 0.52 & 0.93 & 0.69 & 16.892 & 0.95 & 0.57 & 16.296 & 15.7 & -0.52 & 0.52 & 0.93 & 0.72 & 15.746 \\
\hline Matt-Shuttleworth & 0.93 & 0.42 & 12.057 & 10 & -0.32 & 0.32 & 0.96 & 0.84 & 9.974 & 0.94 & 0.42 & 11.955 & 9.8 & -0.34 & 0.34 & 0.96 & 0.85 & 9.832 \\
\hline Turc & 0.94 & 0.33 & 9.462 & -5.9 & 0.2 & 0.28 & 0.98 & 0.9 & 9.151 & 0.95 & 0.32 & 9.179 & -6.8 & 0.21 & 0.28 & 0.98 & 0.91 & 8.954 \\
\hline SVM ETo Model 1 & 0.989 & 0.07 & 2.004 & 0.3 & -0.019 & 0.061 & 0.999 & 0.996 & 1.914 & 0.988 & 0.07 & 1.999 & 0.5 & -0.024 & 0.061 & 0.999 & 0.996 & 1.859 \\
\hline SVM ETo Model 2 & 0.682 & 0.593 & 16.99 & -6.7 & 0.076 & 0.426 & 0.901 & 0.679 & 15.727 & 0.629 & 0.642 & 18.211 & -3.8 & -0.005 & 0.479 & 0.889 & 0.647 & 15.834 \\
\hline SVM ETo Model 4 & 0.985 & 0.112 & 3.197 & 0 & -0.009 & 0.08 & 0.997 & 0.989 & 2.656 & 0.981 & 0.114 & 3.23 & 0.4 & -0.023 & 0.081 & 0.997 & 0.989 & 2.526 \\
\hline SVM ETo Model 5 & 0.983 & 0.128 & 3.656 & -0.1 & -0.005 & 0.085 & 0.996 & 0.985 & 3.082 & 0.976 & 0.148 & 4.198 & -1.4 & 0.031 & 0.102 & 0.995 & 0.981 & 3.698 \\
\hline SVM ETo Model 6 & 0.967 & 0.172 & 4.941 & 0.4 & -0.022 & 0.107 & 0.993 & 0.973 & 3.799 & 0.97 & 0.165 & 4.673 & 0.1 & -0.017 & 0.112 & 0.994 & 0.977 & 3.844 \\
\hline SVM ETo Model 7 & 0.612 & 0.648 & 18.574 & -7.5 & 0.066 & 0.495 & 0.873 & 0.616 & 18.204 & 0.639 & 0.638 & 18.099 & -5.9 & 0.038 & 0.498 & 0.881 & 0.651 & 16.646 \\
\hline SVM ETo Model 8 & 0.549 & 0.695 & 19.906 & -7.8 & 0.048 & 0.54 & 0.848 & 0.559 & 19.93 & 0.559 & 0.717 & 20.323 & -8.9 & 0.084 & 0.571 & 0.834 & 0.56 & 19.957 \\
\hline ELM ETo Model 1 & 0.997 & 0.056 & 1.594 & 0 & 0 & 0.041 & 0.999 & 0.997 & 1.32 & 0.997 & 0.061 & 1.72 & 0 & 0 & 0.044 & 0.999 & 0.997 & 1.421 \\
\hline ELM ETo Model 2 & 0.659 & 0.595 & 17.043 & -4.6 & 0 & 0.447 & 0.896 & 0.677 & 16.035 & 0.62 & 0.643 & 18.23 & -1.9 & -0.07 & 0.49 & 0.886 & 0.646 & 15.921 \\
\hline ELM ETo Model 3 & 0.618 & 0.63 & 18.053 & -5.1 & 0 & 0.488 & 0.88 & 0.637 & 17.388 & 0.607 & 0.653 & 18.526 & -2.1 & -0.071 & 0.513 & 0.878 & 0.635 & 16.462 \\
\hline ELM ETo Model 4 & 0.988 & 0.108 & 3.104 & -0.2 & 0 & 0.073 & 0.997 & 0.989 & 2.453 & 0.985 & 0.111 & 3.14 & 0.1 & -0.011 & 0.075 & 0.997 & 0.99 & 2.362 \\
\hline ELM ETo Model 6 & 0.972 & 0.17 & 4.862 & -0.5 & 0 & 0.109 & 0.993 & 0.974 & 3.975 & 0.975 & 0.163 & 4.63 & -0.6 & 0.001 & 0.113 & 0.994 & 0.977 & 3.955 \\
\hline ELM ETo Model 7 & 0.602 & 0.643 & 18.431 & -5.4 & 0 & 0.499 & 0.873 & 0.622 & 17.861 & 0.621 & 0.644 & 18.277 & -3.9 & -0.027 & 0.506 & 0.876 & 0.644 & 16.478 \\
\hline ELM ETo Model 8 & 0.541 & 0.693 & 19.849 & -6.5 & 0 & 0.544 & 0.844 & 0.561 & 19.812 & 0.552 & 0.714 & 20.253 & -7.5 & 0.035 & 0.571 & 0.831 & 0.563 & 19.669 \\
\hline
\end{tabular}

Notes: (1) Best statistical indicators among each category (Empirical Model, SVM, and ELM) are marked in bold green, while least accurate are marked in bold red.

(2) $R^{2}$, d and NSE are dimensionless; RRMSE, \%Bias and MAPE are in percent; and RMSE, ME, and MAE are in mm/day.

(3) Highlight colors of models indicate the input or independent variables considered, i.e., 
Table 8. Statistical values of empirical and machine learning models used for estimating daily ETo at Alabat Station.

\begin{tabular}{|c|c|c|c|c|c|c|c|c|c|c|c|c|c|c|c|c|c|c|}
\hline \multirow{2}{*}{ MODEL } & \multicolumn{9}{|c|}{ Model Development } & \multicolumn{9}{|c|}{ Model Evaluation } \\
\hline & $\mathbf{R}^{2}$ & RMSE & RRMSE & $\%$ Bias & ME & MAE & $\mathrm{d}$ & NSE & MAPE & $\mathbf{R}^{2}$ & RMSE & RRMSE & $\%$ Bias & ME & MAE & d & NSE & MAPE \\
\hline Hargreaves-Samani & 0.35 & 1.02 & 25.3 & -18.4 & 0.26 & 0.77 & 0.62 & 0.27 & 28.185 & 0.34 & 1.06 & 27.47 & -26 & 0.53 & 0.76 & 0.62 & 0.09 & 30.607 \\
\hline Makkink & 0.96 & 0.6 & 14.789 & 16.3 & -0.54 & 0.54 & 0.94 & 0.75 & 16.332 & 0.97 & 0.56 & 14.544 & 15.3 & -0.52 & 0.52 & 0.94 & 0.74 & 15.268 \\
\hline Matt-Shuttleworth & 0.95 & 0.63 & 15.589 & 15.9 & -0.56 & 0.56 & 0.94 & 0.72 & 15.89 & 0.94 & 0.48 & 12.538 & 11.3 & -0.4 & 0.4 & 0.95 & 0.81 & 11.345 \\
\hline Turc & 0.96 & 0.36 & 9.006 & -3.9 & 0.21 & 0.31 & 0.98 & 0.91 & 8.568 & 0.97 & 0.31 & 8.129 & -5.9 & 0.23 & 0.27 & 0.98 & 0.92 & 7.714 \\
\hline SVM ETo Model 1 & 0.99 & 0.076 & 1.897 & 0.2 & -0.02 & 0.067 & 0.999 & 0.996 & 1.863 & 0.987 & 0.089 & 2.322 & 0 & -0.022 & 0.079 & 0.998 & 0.994 & 2.291 \\
\hline SVM ETo Model 2 & 0.653 & 0.71 & 17.636 & -8.2 & 0.128 & 0.517 & 0.889 & 0.643 & 17.067 & 0.615 & 0.771 & 20.039 & -13.1 & 0.351 & 0.547 & 0.878 & 0.516 & 18.286 \\
\hline SVM ETo Model 4 & 0.986 & 0.127 & 3.144 & -0.1 & -0.007 & 0.092 & 0.997 & 0.989 & 2.899 & 0.981 & 0.134 & 3.493 & -1.4 & 0.032 & 0.097 & 0.996 & 0.985 & 3.088 \\
\hline SVM ETo Model 5 & 0.988 & 0.115 & 2.847 & 0 & -0.007 & 0.083 & 0.998 & 0.991 & 2.5 & 0.971 & 0.168 & 4.358 & -2.8 & 0.066 & 0.124 & 0.994 & 0.977 & 4.195 \\
\hline SVM ETo Model 6 & 0.982 & 0.16 & 3.964 & -0.1 & -0.003 & 0.113 & 0.996 & 0.982 & 3.505 & 0.94 & 0.247 & 6.427 & -5.6 & 0.159 & 0.19 & 0.987 & 0.95 & 6.451 \\
\hline SVM ETo Model 7 & 0.6 & 0.749 & 18.603 & -7.4 & 0.074 & 0.573 & 0.869 & 0.603 & 18.403 & 0.622 & 0.776 & 20.163 & -12.6 & 0.361 & 0.589 & 0.881 & 0.51 & 18.708 \\
\hline SVM ETo Model 8 & 0.564 & 0.783 & 19.44 & -8.6 & 0.087 & 0.602 & 0.851 & 0.566 & 19.773 & 0.538 & 0.91 & 23.658 & -21 & 0.564 & 0.712 & 0.818 & 0.325 & 24.538 \\
\hline ELM ETo Model 1 & 0.997 & 0.064 & 1.578 & 0 & 0 & 0.047 & 0.999 & 0.997 & 1.351 & 0.991 & 0.102 & 2.66 & -0.7 & 0.007 & 0.073 & 0.998 & 0.991 & 2.362 \\
\hline ELM ETo Model 2 & 0.628 & 0.707 & 17.555 & -5.2 & 0 & 0.543 & 0.884 & 0.646 & 17.291 & 0.659 & 0.696 & 18.084 & -6.6 & 0.15 & 0.513 & 0.901 & 0.606 & 16.644 \\
\hline ELM ETo Model 3 & 0.6 & 0.734 & 18.228 & -5.4 & 0 & 0.572 & 0.871 & 0.619 & 17.849 & 0.617 & 0.756 & 19.656 & -11.3 & 0.302 & 0.57 & 0.881 & 0.534 & 18.32 \\
\hline ELM ETo Model 4 & 0.988 & 0.125 & 3.105 & -0.2 & 0 & 0.088 & 0.997 & 0.989 & 2.831 & 0.966 & 0.165 & 4.285 & -2.4 & 0.076 & 0.117 & 0.994 & 0.978 & 3.549 \\
\hline ELM ETo Model 6 & 0.98 & 0.161 & 3.999 & -0.4 & 0 & 0.114 & 0.995 & 0.982 & 3.619 & 0.947 & 0.229 & 5.952 & -5.5 & 0.155 & 0.187 & 0.989 & 0.957 & 6.354 \\
\hline ELM ETo Model 7 & 0.586 & 0.746 & 18.543 & -5.6 & 0 & 0.583 & 0.865 & 0.605 & 18.333 & 0.618 & 0.758 & 19.695 & -10.9 & 0.301 & 0.569 & 0.883 & 0.532 & 18.096 \\
\hline ELM ETo Model 8 & 0.547 & 0.782 & 19.431 & -6.3 & 0 & 0.612 & 0.846 & 0.567 & 19.622 & 0.553 & 0.859 & 22.34 & -19 & 0.491 & 0.672 & 0.83 & 0.398 & 23.342 \\
\hline
\end{tabular}

Notes: (1) Best statistical indicators among each category (Empirical Model, SVM, and ELM) are marked in bold green, while least accurate are marked in bold red.

(2) $\mathrm{R}^{2}$, d and NSE are dimensionless; RRMSE, \%Bias and MAPE are in percent; and RMSE, ME, and MAE are in mm/day.

(3) Highlight colors of models indicate the input or independent variables considered, i.e., 
Table 9. Statistical values of empirical and machine learning models used for estimating daily ETo at Tayabas Station.

\begin{tabular}{|c|c|c|c|c|c|c|c|c|c|c|c|c|c|c|c|c|c|c|}
\hline \multirow{2}{*}{ MODEL } & \multicolumn{9}{|c|}{ Model Development } & \multicolumn{9}{|c|}{ Model Evaluation } \\
\hline & $\mathbf{R}^{2}$ & RMSE & RRMSE & $\%$ Bias & ME & MAE & $\mathrm{d}$ & NSE & MAPE & $\mathbf{R}^{2}$ & RMSE & RRMSE & $\%$ Bias & ME & MAE & d & NSE & MAPE \\
\hline Hargreaves-Samani & 0.29 & 1.23 & 35.626 & -39.8 & 0.87 & 0.94 & 0.58 & -0.44 & 41.167 & 0.34 & 1.12 & 31.018 & -31.5 & 0.69 & 0.84 & 0.61 & -0.1 & 34.382 \\
\hline Makkink & 0.97 & 0.53 & 15.299 & 16.6 & -0.5 & 0.5 & 0.94 & 0.73 & 16.582 & 0.96 & 0.54 & 14.975 & 15.6 & -0.5 & 0.5 & 0.94 & 0.74 & 15.602 \\
\hline Matt-Shuttleworth & 0.96 & 0.4 & 11.535 & 10.5 & -0.34 & 0.34 & 0.96 & 0.85 & 10.543 & 0.95 & 0.45 & 12.357 & 11.4 & -0.38 & 0.38 & 0.96 & 0.83 & 11.377 \\
\hline Turc & 0.97 & 0.28 & 8.097 & -5.9 & 0.21 & 0.24 & 0.98 & 0.93 & 7.562 & 0.97 & 0.3 & 8.211 & -5.9 & 0.21 & 0.26 & 0.98 & 0.92 & 7.61 \\
\hline SVM ETo Model 1 & 0.989 & 0.07 & 2.015 & 0.3 & -0.021 & 0.062 & 0.999 & 0.995 & 1.957 & 0.989 & 0.074 & 2.031 & 0.3 & -0.021 & 0.063 & 0.999 & 0.995 & 1.91 \\
\hline SVM ETo Model 2 & 0.708 & 0.552 & 15.996 & -5.8 & 0.056 & 0.409 & 0.912 & 0.71 & 15.158 & 0.68 & 0.591 & 16.323 & -4.7 & 0.009 & 0.452 & 0.9 & 0.696 & 15.349 \\
\hline SVM ETo Model 4 & 0.99 & 0.089 & 2.592 & 0 & -0.005 & 0.067 & 0.998 & 0.992 & 2.234 & 0.987 & 0.106 & 2.915 & 0.2 & -0.011 & 0.075 & 0.998 & 0.99 & 2.363 \\
\hline SVM ETo Model 5 & 0.985 & 0.107 & 3.105 & 0.1 & -0.011 & 0.076 & 0.997 & 0.989 & 2.611 & 0.976 & 0.148 & 4.094 & -1.3 & 0.029 & 0.102 & 0.995 & 0.981 & 3.395 \\
\hline SVM ETo Model 6 & 0.983 & 0.126 & 3.667 & 0 & -0.005 & 0.084 & 0.996 & 0.985 & 2.878 & 0.977 & 0.162 & 4.463 & -0.6 & 0.008 & 0.106 & 0.994 & 0.977 & 3.521 \\
\hline SVM ETo Model 7 & 0.668 & 0.583 & 16.914 & -6 & 0.043 & 0.45 & 0.897 & 0.676 & 16.558 & 0.644 & 0.623 & 17.217 & -4.7 & 0.001 & 0.492 & 0.887 & 0.662 & 16.334 \\
\hline SVM ETo Model 8 & 0.587 & 0.652 & 18.887 & -7.4 & 0.049 & 0.507 & 0.863 & 0.595 & 18.942 & 0.573 & 0.701 & 19.363 & -8.9 & 0.09 & 0.545 & 0.846 & 0.572 & 19.341 \\
\hline ELM ETo Model 1 & 0.997 & 0.056 & 1.63 & 0 & 0 & 0.042 & 0.999 & 0.997 & 1.386 & 0.995 & 0.074 & 2.047 & 0 & -0.001 & 0.051 & 0.999 & 0.995 & 1.595 \\
\hline ELM ETo Model 2 & 0.699 & 0.546 & 15.838 & -4.2 & 0 & 0.416 & 0.912 & 0.715 & 15.108 & 0.661 & 0.601 & 16.617 & -3 & -0.046 & 0.468 & 0.897 & 0.685 & 15.412 \\
\hline ELM ETo Model 3 & 0.666 & 0.576 & 16.7 & -4.6 & 0 & 0.449 & 0.899 & 0.684 & 16.183 & 0.624 & 0.636 & 17.585 & -3.5 & -0.034 & 0.501 & 0.883 & 0.647 & 16.327 \\
\hline ELM ETo Model 4 & 0.992 & 0.086 & 2.493 & -0.1 & 0 & 0.063 & 0.998 & 0.993 & 2.109 & 0.986 & 0.116 & 3.211 & 0.2 & -0.008 & 0.075 & 0.997 & 0.988 & 2.369 \\
\hline ELM ETo Model 6 & 0.984 & 0.124 & 3.595 & -0.2 & 0 & 0.084 & 0.996 & 0.985 & 2.916 & 0.972 & 0.175 & 4.831 & -1 & 0.016 & 0.111 & 0.993 & 0.973 & 3.79 \\
\hline ELM ETo Model 7 & 0.655 & 0.586 & 16.983 & -4.7 & 0 & 0.457 & 0.895 & 0.673 & 16.541 & 0.609 & 0.653 & 18.036 & -3.8 & -0.02 & 0.506 & 0.879 & 0.629 & 16.554 \\
\hline ELM ETo Model 8 & 0.577 & 0.651 & 18.862 & -5.9 & 0 & 0.512 & 0.861 & 0.596 & 18.847 & 0.574 & 0.692 & 19.111 & -7.6 & 0.052 & 0.54 & 0.849 & 0.583 & 18.944 \\
\hline
\end{tabular}

Notes: (1) Best statistical indicators among each category (Empirical Model, SVM, and ELM) are marked in bold green, while least accurate are marked in bold red.

(2) $\mathrm{R}^{2}$, d and NSE are dimensionless; RRMSE, \%Bias and MAPE are in percent; and RMSE, ME, and MAE are in mm/day.

(3) Highlight colors of models indicate the input or independent variables considered, i.e., 
Table 10. Statistical values of empirical and machine learning models used for estimating daily ETo at Ambulong Station.

\begin{tabular}{|c|c|c|c|c|c|c|c|c|c|c|c|c|c|c|c|c|c|c|}
\hline \multirow{2}{*}{ MODEL } & \multicolumn{9}{|c|}{ Model Development } & \multicolumn{9}{|c|}{ Model Evaluation } \\
\hline & $\mathbf{R}^{2}$ & RMSE & RRMSE & $\%$ Bias & ME & MAE & d & NSE & MAPE & $\mathbf{R}^{2}$ & RMSE & RRMSE & $\%$ Bias & ME & MAE & d & NSE & MAPE \\
\hline Hargreaves-Samani & 0.28 & 1.12 & 30.099 & -30.9 & 0.68 & 0.81 & 0.61 & -0.15 & 33.534 & 0.34 & 1.01 & 25.519 & -22.1 & 0.48 & 0.73 & 0.65 & 0.14 & 26.88 \\
\hline Makkink & 0.93 & 0.77 & 20.734 & 21.6 & -0.72 & 0.72 & 0.88 & 0.46 & 21.585 & 0.89 & 0.88 & 22.264 & 22 & -0.8 & 0.8 & 0.85 & 0.34 & 21.981 \\
\hline Matt-Shuttleworth & 0.88 & 0.71 & 18.985 & 17 & -0.61 & 0.61 & 0.89 & 0.54 & 17.056 & 0.82 & 0.85 & 21.625 & 18.7 & -0.72 & 0.72 & 0.85 & 0.38 & 18.717 \\
\hline Turc & 0.93 & 0.29 & 7.74 & 0.3 & 0.01 & 0.22 & 0.98 & 0.92 & 6.52 & 0.89 & 0.37 & 9.488 & 1.9 & -0.06 & 0.26 & 0.97 & 0.88 & 7.191 \\
\hline SVM ETo Model 1 & 0.989 & 0.091 & 2.429 & 0.1 & -0.009 & 0.071 & 0.998 & 0.993 & 2.255 & 0.951 & 0.215 & 5.441 & 0.9 & -0.043 & 0.135 & 0.99 & 0.961 & 3.94 \\
\hline SVM ETo Model 2 & 0.789 & 0.479 & 12.842 & -3.8 & 0.039 & 0.361 & 0.94 & 0.791 & 12.196 & 0.725 & 0.558 & 14.123 & -4 & 0.012 & 0.424 & 0.914 & 0.735 & 13.308 \\
\hline SVM ETo Model 4 & 0.955 & 0.205 & 5.485 & 0.1 & -0.017 & 0.145 & 0.99 & 0.962 & 4.344 & 0.889 & 0.332 & 8.397 & 3 & -0.129 & 0.211 & 0.976 & 0.906 & 5.708 \\
\hline SVM ETo Model 5 & 0.975 & 0.152 & 4.07 & -0.1 & -0.008 & 0.104 & 0.995 & 0.979 & 3.451 & 0.962 & 0.2 & 5.071 & -0.2 & -0.007 & 0.141 & 0.991 & 0.966 & 4.294 \\
\hline SVM ETo Model 6 & 0.937 & 0.243 & 6.53 & 0.5 & -0.033 & 0.168 & 0.986 & 0.946 & 5.119 & 0.886 & 0.339 & 8.591 & 1.9 & -0.095 & 0.234 & 0.975 & 0.902 & 6.444 \\
\hline SVM ETo Model 7 & 0.702 & 0.56 & 15.027 & -3.9 & 0.015 & 0.444 & 0.912 & 0.714 & 14.403 & 0.656 & 0.619 & 15.679 & -1.7 & -0.093 & 0.486 & 0.885 & 0.674 & 14.484 \\
\hline SVM ETo Model 8 & 0.667 & 0.596 & 15.996 & -4.9 & 0.031 & 0.472 & 0.898 & 0.676 & 15.626 & 0.595 & 0.68 & 17.216 & -5.6 & 0.033 & 0.524 & 0.862 & 0.606 & 16.419 \\
\hline ELM ETo Model 1 & 0.993 & 0.087 & 2.342 & -0.1 & 0 & 0.065 & 0.998 & 0.993 & 2.115 & 0.95 & 0.221 & 5.609 & 0.8 & -0.037 & 0.139 & 0.989 & 0.958 & 4.019 \\
\hline ELM ETo Model 2 & 0.785 & 0.472 & 12.672 & -2.8 & 0 & 0.362 & 0.941 & 0.797 & 12.038 & 0.704 & 0.571 & 14.474 & -2.4 & -0.052 & 0.445 & 0.907 & 0.722 & 13.54 \\
\hline ELM ETo Model 3 & 0.719 & 0.541 & 14.506 & -3.4 & 0 & 0.43 & 0.918 & 0.733 & 13.958 & 0.663 & 0.615 & 15.576 & -2 & -0.084 & 0.488 & 0.885 & 0.678 & 14.607 \\
\hline ELM ETo Model 4 & 0.961 & 0.201 & 5.392 & -0.4 & 0 & 0.147 & 0.991 & 0.963 & 4.429 & 0.885 & 0.336 & 8.511 & 2.9 & -0.136 & 0.22 & 0.975 & 0.904 & 5.927 \\
\hline ELM ETo Model 6 & 0.944 & 0.239 & 6.411 & -0.7 & 0 & 0.172 & 0.986 & 0.948 & 5.363 & 0.891 & 0.332 & 8.415 & 0.8 & -0.062 & 0.236 & 0.975 & 0.906 & 6.603 \\
\hline ELM ETo Model 7 & 0.699 & 0.561 & 15.035 & -3.7 & 0 & 0.446 & 0.911 & 0.714 & 14.477 & 0.646 & 0.632 & 16.014 & -1.2 & -0.119 & 0.501 & 0.877 & 0.66 & 14.793 \\
\hline ELM ETo Model 8 & 0.661 & 0.595 & 15.961 & -4.2 & 0 & 0.473 & 0.896 & 0.677 & 15.608 & 0.59 & 0.679 & 17.207 & -4.6 & -0.008 & 0.529 & 0.859 & 0.607 & 16.379 \\
\hline
\end{tabular}

Notes: (1) Best statistical indicators among each category (Empirical Model, SVM, and ELM) are marked in bold green, while least accurate are marked in bold red.

(2) $R^{2}$, d and NSE are dimensionless; RRMSE, \%Bias and MAPE are in percent; and RMSE, ME, and MAE are in mm/day.

(3) Highlight colors of models indicate the input or independent variables considered, i.e., 
Table 11. Statistical values of empirical and machine learning models in estimating daily ETo at Tanay Station.

\begin{tabular}{|c|c|c|c|c|c|c|c|c|c|c|c|c|c|c|c|c|c|c|}
\hline \multirow{2}{*}{ MODEL } & \multicolumn{9}{|c|}{ Model Development } & \multicolumn{9}{|c|}{ Model Evaluation } \\
\hline & $\mathbf{R}^{2}$ & RMSE & RRMSE & $\%$ Bias & ME & MAE & $\mathrm{d}$ & NSE & MAPE & $\mathbf{R}^{2}$ & RMSE & RRMSE & $\%$ Bias & ME & MAE & d & NSE & MAPE \\
\hline Hargreaves-Samani & 0.34 & 1.23 & 40.001 & -47.1 & 0.9 & 0.98 & 0.6 & -0.46 & 48.677 & 0.37 & 1.1 & 33.497 & -35.6 & 0.68 & 0.85 & 0.63 & -0.06 & 39.055 \\
\hline Makkink & 0.95 & 0.3 & 9.903 & 7.9 & -0.2 & 0.24 & 0.98 & 0.91 & 9.426 & 0.95 & 0.36 & 11.051 & 9.4 & -0.27 & 0.3 & 0.97 & 0.89 & 10.332 \\
\hline Matt-Shuttleworth & 0.93 & 0.41 & 13.484 & 9.9 & -0.31 & 0.32 & 0.96 & 0.83 & 10.433 & 0.9 & 0.56 & 17 & 13.4 & -0.44 & 0.45 & 0.93 & 0.73 & 13.629 \\
\hline Turc & 0.95 & 0.46 & 15.171 & -14.6 & 0.41 & 0.42 & 0.95 & 0.79 & 15.232 & 0.95 & 0.42 & 12.776 & -11.6 & 0.35 & 0.37 & 0.96 & 0.85 & 12.518 \\
\hline SVM ETo Model 1 & 0.989 & 0.07 & 2.3 & 0.2 & -0.014 & 0.062 & 0.999 & 0.995 & 2.303 & 0.992 & 0.072 & 2.19 & 0.1 & -0.01 & 0.061 & 0.999 & 0.995 & 2.161 \\
\hline SVM ETo Model 2 & 0.798 & 0.443 & 14.472 & -4.4 & 0.017 & 0.344 & 0.945 & 0.809 & 14.293 & 0.822 & 0.445 & 13.55 & -4.5 & 0.034 & 0.347 & 0.95 & 0.827 & 13.366 \\
\hline SVM ETo Model 4 & 0.989 & 0.1 & 3.253 & -0.2 & 0 & 0.075 & 0.998 & 0.99 & 2.838 & 0.99 & 0.097 & 2.961 & 0 & -0.003 & 0.074 & 0.998 & 0.992 & 2.525 \\
\hline SVM ETo Model 5 & 0.965 & 0.177 & 5.778 & -0.2 & -0.008 & 0.124 & 0.992 & 0.97 & 4.754 & 0.937 & 0.226 & 6.868 & 2.1 & -0.078 & 0.161 & 0.989 & 0.956 & 5.414 \\
\hline SVM ETo Model 6 & 0.962 & 0.186 & 6.079 & -0.4 & -0.005 & 0.132 & 0.991 & 0.966 & 5.099 & 0.94 & 0.221 & 6.716 & 1.9 & -0.07 & 0.159 & 0.989 & 0.958 & 5.361 \\
\hline SVM ETo Model 7 & 0.781 & 0.461 & 15.042 & -4.4 & 0.01 & 0.358 & 0.94 & 0.794 & 14.905 & 0.814 & 0.449 & 13.661 & -3.8 & 0.018 & 0.355 & 0.95 & 0.824 & 13.465 \\
\hline SVM ETo Model 8 & 0.672 & 0.568 & 18.528 & -6.7 & 0.023 & 0.44 & 0.902 & 0.687 & 18.632 & 0.616 & 0.638 & 19.41 & -1.9 & -0.112 & 0.509 & 0.887 & 0.646 & 18.765 \\
\hline ELM ETo Model 1 & 0.996 & 0.062 & 2.031 & -0.1 & 0 & 0.048 & 0.999 & 0.996 & 1.806 & 0.995 & 0.07 & 2.143 & 0 & 0.001 & 0.053 & 0.999 & 0.996 & 1.869 \\
\hline ELM ETo Model 2 & 0.799 & 0.438 & 14.304 & -3.7 & 0 & 0.339 & 0.946 & 0.814 & 13.981 & 0.8 & 0.462 & 14.071 & -3.6 & 0.008 & 0.362 & 0.946 & 0.814 & 13.557 \\
\hline ELM ETo Model 3 & 0.786 & 0.452 & 14.756 & -3.9 & 0 & 0.352 & 0.942 & 0.802 & 14.559 & 0.81 & 0.45 & 13.691 & -3.3 & 0.002 & 0.355 & 0.949 & 0.824 & 13.398 \\
\hline ELM ETo Model 4 & 0.989 & 0.1 & 3.274 & -0.2 & 0 & 0.075 & 0.998 & 0.99 & 2.84 & 0.99 & 0.101 & 3.062 & 0 & -0.003 & 0.075 & 0.998 & 0.991 & 2.561 \\
\hline ELM ETo Model 6 & 0.964 & 0.185 & 6.026 & -0.6 & 0 & 0.132 & 0.992 & 0.967 & 5.088 & 0.941 & 0.219 & 6.679 & 1.7 & -0.066 & 0.158 & 0.989 & 0.958 & 5.34 \\
\hline ELM ETo Model 7 & 0.781 & 0.458 & 14.93 & -4.1 & 0 & 0.356 & 0.941 & 0.797 & 14.799 & 0.805 & 0.456 & 13.886 & -3.6 & 0.007 & 0.363 & 0.947 & 0.819 & 13.661 \\
\hline ELM ETo Model 8 & 0.669 & 0.566 & 18.454 & -6 & 0 & 0.44 & 0.901 & 0.69 & 18.518 & 0.608 & 0.645 & 19.625 & -1.1 & -0.14 & 0.516 & 0.883 & 0.638 & 18.797 \\
\hline
\end{tabular}

Notes: (1) Best statistical indicators among each category (Empirical Model, SVM, and ELM) are marked in bold green, while least accurate are marked in bold red.

(2) $\mathrm{R}^{2}$, d and NSE are dimensionless; RRMSE, \%Bias and MAPE are in percent; and RMSE, ME, and MAE are in mm/day.

(3) Highlight colors of models indicate the input or independent variables considered, i.e., 
Table 12. Computed GPI (and ranking) for different empirical and machine learning models used for the estimation of daily ETo.

\begin{tabular}{|c|c|c|c|c|c|c|c|c|c|c|c|c|c|c|}
\hline \multirow{2}{*}{ MODEL } & \multicolumn{7}{|c|}{ Model Development } & \multicolumn{7}{|c|}{ Model Evaluation } \\
\hline & UPLB & Sangley & Infanta & Alabat & Tayabas & Ambulong & Tanay & UPLB & Sangley & Infanta & Alabat & Tayabas & Ambulong & Tanay \\
\hline Hargreaves-Samani & $-4.36(21)$ & $-4.74(21)$ & $-4.85(21)$ & $-3.63(21)$ & $-5.08(21)$ & $-4.99(21)$ & $-5.44(21)$ & $-4.62(21)$ & $-4.14(21)$ & $-4.72(21)$ & $-4.04(21)$ & $-4.68(21)$ & $-4.36(21)$ & $-5.05(21)$ \\
\hline & $-0.15(11)$ & $-1.66(19)$ & $-0.14(11)$ & $0.04(10)$ & $-0.14(11)$ & $-1.67(20)$ & $0.54(9)$ & $-0.07(11)$ & $-2.82(19)$ & $0(11)$ & $0.15(11)$ & $-0.07(11)$ & $-2.22(20)$ & $0.42(9)$ \\
\hline Priestley-Taylor & $-0.88(16)$ & $-0.77(16)$ & $-1.43(20)$ & $-1.61(19)$ & $-1.6(20)$ & $-0.74(14)$ & $-2.93(20)$ & $-2.69(20)$ & $0.28(10)$ & $-1.47(20)$ & $-1.94(18)$ & $-1.86(20)$ & -0.49 (12) & $-2.82(20)$ \\
\hline Matt-Shuttleworth & $0.26(10)$ & $-2.11(20)$ & $0.67(10)$ & $-0.06(11)$ & $0.52(10)$ & $-1.23(19)$ & $0.16(10)$ & $0.81(10)$ & $-3.26(20)$ & $0.77(10)$ & $0.68(10)$ & $0.5(10)$ & $-1.94(19)$ & $-0.53(17)$ \\
\hline Turc & $1.52(9)$ & $0.91(9)$ & $0.91(9)$ & $1.47(9)$ & $0.91(9)$ & $0.96(9)$ & $-0.32(14)$ & $0.88(9)$ & $0.84(9)$ & $1.06(9)$ & $1.52(9)$ & $1.12(9)$ & $1.38(9)$ & $0.04(10)$ \\
\hline SVM ETo Model 1 & $2.39(2)$ & $1.79(2)$ & $2.01(2)$ & $2.91(2)$ & $1.79(2)$ & $1.89(2)$ & $1.43(2)$ & $2.04(2)$ & $2.18(2)$ & $2.15(2)$ & $2.62(1)$ & $2.17(2)$ & $2.38(2)$ & $1.73(2)$ \\
\hline SVM ETo Model 2 & $-0.41(12)$ & $-0.15(11)$ & $-0.48(12)$ & $-0.98(13)$ & $-0.5(13)$ & $-0.21(11)$ & $-0.27(12)$ & $-1.68(17)$ & $-0.48(12)$ & $-0.76(12)$ & $-1.65(15)$ & $-0.64(12)$ & $-0.21(10)$ & $-0.16(12)$ \\
\hline SVM ETo Model 3 & $-0.57(15)$ & $-0.4(13)$ & $-0.77(14)$ & $-1.25(16)$ & $-0.68(14)$ & $-0.71(13)$ & $-0.3(13)$ & $-1.67(16)$ & $-0.86(14)$ & $-0.87(16)$ & $-1.89(17)$ & $-0.95(15)$ & $-0.52(13)$ & $-0.15(11)$ \\
\hline SVM ETo Model 4 & $2.03(5)$ & $1.55(4)$ & $1.88(4)$ & $2.7(6)$ & $1.73(4)$ & $1.41(6)$ & $1.34(3)$ & $1.8(5)$ & $1.64(3)$ & $2.01(4)$ & $2.41(3)$ & $2.06(3)$ & $1.76(5)$ & $1.65(3)$ \\
\hline SVM ETo Model 6 & $1.93(7)$ & $1.26(7)$ & $1.67(8)$ & $2.56(7)$ & $1.61(8)$ & $1.24(7)$ & $1.02(8)$ & $1.71(7)$ & $1.22(7)$ & $1.82(8)$ & $1.72(8)$ & $1.85(6)$ & $1.64(7)$ & $1.1(6)$ \\
\hline SVM ETo Model 7 & $-1.12(18)$ & $-0.53(15)$ & $-0.9(17)$ & $-1.33(17)$ & $-0.74(16)$ & $-0.79(15)$ & $-0.37(17)$ & $-1.55(15)$ & $-1.42(17)$ & $-0.79(14)$ & $-1.73(16)$ & $-0.89(14)$ & $-0.7(15)$ & $-0.19(13)$ \\
\hline SVM ETo Model 8 & $-1.3(19)$ & $-1.52(18)$ & $-1.25(18)$ & $-1.66(20)$ & $-1.21(18)$ & $-1.07(18)$ & $-1.03(19)$ & $-1.51(13)$ & $-1.37(16)$ & $-1.39(19)$ & $-3.02(20)$ & $-1.48(19)$ & $-1.33(18)$ & $-1.49(18)$ \\
\hline ELM ETo Model 1 & $2.4(1)$ & $1.86(1)$ & $2.07(1)$ & $2.98(1)$ & $1.85(1)$ & $1.91(1)$ & $1.47(1)$ & $2.08(1)$ & $2.22(1)$ & $2.2(1)$ & $2.6(2)$ & $2.2(1)$ & $2.34(4)$ & $1.75(1)$ \\
\hline ELM ETo Model 2 & $-0.49(13)$ & $-0.05(10)$ & $-0.54(13)$ & $-0.82(12)$ & $-0.5(12)$ & $-0.16(10)$ & $-0.24(11)$ & $-1.78(18)$ & $-0.04(11)$ & $-0.78(13)$ & $-0.86(12)$ & $-0.72(13)$ & $-0.31(11)$ & $-0.27(16)$ \\
\hline ELM ETo Model 3 & $-0.56(14)$ & $-0.29(12)$ & $-0.8(15)$ & $-1.04(14)$ & $-0.7(15)$ & $-0.66(12)$ & $-0.32(15)$ & $-1.84(19)$ & $-0.53(13)$ & -0.89 (17) & $-1.32(14)$ & $-0.98(16)$ & -0.68 & $-0.2(14)$ \\
\hline ELM ETo Model 4 & $2.01(6)$ & $1.56(3)$ & $1.9(3)$ & $2.72(5)$ & $1.75(3)$ & $1.41(5)$ & $1.34(4)$ & $1.73(6)$ & $1.62(4)$ & $2.03(3)$ & $2.29(4)$ & $2.04(4)$ & $1.72(6)$ & $1.63(4)$ \\
\hline ELM ETo Model 5 & $2.35(3)$ & $1.53(5)$ & $1.84(5)$ & $2.78(3)$ & $1.67(6)$ & $1.66(3)$ & $1.06(5)$ & $1.93(4)$ & $1.52(5)$ & $1.88(5)$ & $2.27(5)$ & $1.84(7)$ & $2.36(3)$ & $1.09(7)$ \\
\hline ELM ETo Model 6 & $1.93(8)$ & $1.25(8)$ & $1.68(7)$ & $2.56(8)$ & $1.62(7)$ & $1.23(8)$ & $1.02(7)$ & $1.62(8)$ & $1.18(8)$ & $1.82(7)$ & $1.92(7)$ & $1.8(8)$ & $1.63(8)$ & $1.11(5)$ \\
\hline ELM ETo Model 7 & $-1.08(17)$ & $-0.44(14)$ & $-0.89(16)$ & -1.15 (15) & $-0.77(17)$ & $-0.8(16)$ & $-0.35(16)$ & $-1.54(14)$ & $-1.14(15)$ & $-0.84(15)$ & $-1.32(13)$ & -1.08 (17) & $-0.8(16)$ & $-0.25(15)$ \\
\hline \multirow{2}{*}{$\frac{E L M \text { ETo Model 8 }}{\text { Notes: }}$} & $-1.34(20)$ & -1.32 (17) & -1.26 (19) & $-1.46(18)$ & $-1.22(19)$ & $-1.06(17)$ & $-1.02(18)$ & $-1.49(12)$ & $-1.92(18)$ & $-1.38(18)$ & $-2.18(19)$ & $-1.42(18)$ & $-1.32(17)$ & $-1.54(19)$ \\
\hline & $\begin{array}{l}\text { (2) Highligl } \\
\text { considered, }\end{array}$ & $t$ colors of $m$ & & & & & $f(T)$ & $\mathrm{f}(\mathrm{T}, \mathrm{Rs})$ & $\mathrm{f}(\mathrm{T}, \mathrm{Rs}, \mathrm{Uz})$ & & f ( T, RH, Rs) & & & \\
\hline
\end{tabular}




\subsection{Comparison across Machine Learning Models}

\subsubsection{Comparison of Models across Input Combinations}

Overall, models with $R_{s}$ data as the input variable, such as Models 1, 4, 5, and 6, performed best both in SVM and ELM, with excellent results based on their values of RRMSE and NSE. $R_{S}$ data represent the solar resources in a specific location available to vaporize water, which is considered an important factor, together with air temperature, for the occurrence of ETo [1]. In particular, the estimates of Model 1 perfectly fitted the actual value of FAO-56 PM, with the $\mathrm{R}^{2}$ ranging from 0.95 to 0.99 , an RMSE of 0.07 to $0.22 \mathrm{~mm} /$ day, an RRMSE of 1.72 to $5.44 \%$, an MAE of 0.04 to $0.13 \mathrm{~mm} /$ day, and an NSE of 0.95 to 0.99 . On average, the estimates of Model 1 are only 1.4 to $4.0 \%$ divergent from the standard FAO-56 PM daily ETo. On the other hand, Model 2, which has the same input combination as Model 1, except that it has $R_{a}$ instead of $R_{s}$, performed satisfactorily, with an $\mathrm{R}^{2}$ of $0.62-0.82$, RMSE of 0.45 to $0.77 \mathrm{~mm}$ /day, RRMSE of 12.82 to $20.03 \%$, MAE of 0.35 to $0.62 \mathrm{~mm} /$ day, and NSE of 0.51 to 0.82 . The estimates of Model 2 are 12.61 to $19.83 \%$ on average divergent from the standard FAO-56 PM daily ETo. This shows the importance of $\mathrm{R}_{\mathrm{S}}$ in the estimation of ETo, which cannot be replaced with extraterrestrial solar radiation $\mathrm{R}_{\mathrm{a}}$, even with the presence of both $\mathrm{RH}$ and $\mathrm{U}_{\mathrm{z}}$ data.

TSR-based Model 4 and TSW-based Model 5 show relatively comparable performances based on the average statistical indicators. On average, the estimated daily ETos of Model 4 and Model 5 are only 2.4 to $8.1 \%$ and 3.4 to $7.6 \%$ divergent from the standard FAO-56 PM daily ETo, respectively. Model 4 fitted with $\mathrm{R}^{2}$ ranging from 0.89 to 0.99 , an RMSE of 0.10 to $0.33 \mathrm{~mm} /$ day, an RRMSE of 2.9 to $8.5 \%$, an MAE of 0.07 to $0.22 \mathrm{~mm} /$ day, and an NSE of 0.91 to 0.99 , while Model 5 fitted with $\mathrm{R}^{2}$ ranges 0.92 to 0.98 , an RMSE of 0.12 to $0.29 \mathrm{~mm} /$ day, an RRMSE of 3.2 to $6.8 \%$, an MAE of 0.09 to $0.18 \mathrm{~mm} /$ day, and an NSE of 0.95 to 0.98 . When compared to Model 1, Models 4 and 5 RMSE decreased by $44.4 \%$, or $0.06 \mathrm{~mm} /$ day, and MAE decreased by $38.9 \%$ or $0.04 \mathrm{~mm} /$ day. Nevertheless, considering the GPI ranking, Model 5 performed better than Model 4 at the UPLB, Alabat, and Ambulong stations, while the opposite was observed for the other stations.

\subsubsection{Comparison of Models between SVM and ELM}

Based on the computed statistical indicators, the SVM developed using the RBF kernel and the ELM model generally exhibited identical performances in estimating daily ETo for all stations and all input combinations, during both the model development and evaluation phases, with average differences in RMSE of $0.002 \mathrm{~mm} /$ day and in MAE of $0.003 \mathrm{~mm} /$ day. In terms of GPI ranking, ELM performed better than SVM for most stations and model inputs, especially in the model evaluation phase. This observation shows that during the model evaluation phase, the ELM model tends to overfit the data, as evidenced by the almost negligible values of $\mathrm{ME}$.

Table 13 presents the average run time, or the time used for the computation, of the SVM and ELM models for ETo estimation. The time needed for running the SVM models ranged from 79.21 to $223.62 \mathrm{~s}$, while the ELM models displayed a lower range, from 83.99 to 98.94 s. For the SVM models, it can be observed that the models with higher accuracy, such as Models 1, 4, 5, and 6, have a relatively faster run time compared to the other models. This can be attributed to the lower time spent in the optimization of hyperparameters through grid searching. Overall, running an ELM model for ETo estimation is almost two times faster than running SVM models. Given that SVM and ELM models can achieve identical accuracy in ETo estimation in the region, ELM is preferred when run time is considered. 
Table 13. Average run time (in seconds) of SVM and ELM under different input combinations in the estimation of daily ETo.

\begin{tabular}{cccc}
\hline Model & Input Combinations & SVM & ELM \\
\hline Model 1 & $\mathrm{T}_{\max }, \mathrm{T}_{\min }, \mathrm{RH}, \mathrm{R}_{\mathrm{s}}, \mathrm{U}_{\mathrm{z}}$ & 79.21 & 96.61 \\
Model 2 & $\mathrm{T}_{\max }, \mathrm{T}_{\min }, \mathrm{RH}, \mathrm{R}_{\mathrm{a}}, \mathrm{U}_{\mathrm{z}}$ & 211.14 & 98.94 \\
Model 3 & $\mathrm{T}_{\max }, \mathrm{T}_{\min }, \mathrm{RH}, \mathrm{U}_{\mathrm{z}}$ & 209.93 & 92.88 \\
Model 4 & $\mathrm{T}_{\max }, \mathrm{T}_{\min }, \mathrm{RH}, \mathrm{R}_{\mathrm{s}}$ & 130.37 & 87.08 \\
Model 5 & $\mathrm{T}_{\max }, \mathrm{T}_{\min }, \mathrm{R}_{\mathrm{s}}, \mathrm{U}_{\mathrm{z}}$ & 116.71 & 87.01 \\
Model 6 & $\mathrm{T}_{\max }, \mathrm{T}_{\min }, \mathrm{R}_{\mathrm{s}}$ & 169.29 & 87.10 \\
Model 7 & $\mathrm{T}_{\max }, \mathrm{T}_{\min }, \mathrm{RH}$ & 223.62 & 86.00 \\
Model 8 & $\mathrm{T}_{\max }, \mathrm{T}_{\min }$ & 169.07 & 83.99 \\
\hline
\end{tabular}

\subsection{Comparison between Empirical and Machine Learning Models}

In general, the accuracy of SVM and ELM models in estimating daily ETo is much better compared to empirical models. This is apparent from the ranking of the computed GPIs of all studied models across stations in Table 12. When comparing models with inputs of only air temperature, we see that Model 8 of the machine learning model achieves better performance than the Hargreaves-Samani equation, with an average increase in $\mathrm{R}^{2}$ of $44.4 \%$, RMSE of $33.5 \%$ or $0.37 \mathrm{~mm} /$ day, and MAE of $30.7 \%$ or $0.26 \mathrm{~mm} /$ day. Based on the values of both RRMSE and NSE, the Hargreaves-Samani equation has a poor modeling capability, while Model 8 is concluded to be acceptable. On the average, estimates of Model 8 are 16.4 to $24.5 \%$ divergent from the actual values, which is relatively better than the 26.9 to $39.1 \%$ of the Hargreaves-Samani equation.

Empirical models with $\mathrm{R}_{\mathrm{S}}$ as one of the inputs (TSR-, TSW-, and TS-based) proved to have an acceptable to satisfactory modeling capability, based on the computed average RRMSE and NSE across stations. With the same input combinations, machine learning models provided an improved performance with excellent results (RRMSE $<10 \%$ and NSE > 0.8). Compared to the best TS-based model, Model 6 of the machine learning models improved the RMSE by $62 \%$ or $0.41 \mathrm{~mm} /$ day, and MAE by $71.0 \%$ or $0.42 \mathrm{~mm} /$ day. The estimates of Model 6 deviate by 3.5 to $8.0 \%$ on average from the actual values, which is relatively better than the 9.85 to $24.4 \%$ of TS-based models. On the other hand, Model 5 , when compared to its analogous TSW-based Matt-Shuttleworth equation, achieves an average increase in accuracy of $76.5 \%$ or $0.46 \mathrm{~mm} /$ day in terms of RRMSE, and $75.2 \%$ or $0.39 \mathrm{~mm} /$ day in terms of MAE. The estimates of Model 5 are on average deviant from the actual value by 3.4 to $7.6 \%$, which is better than the Matt-Shuttleworth equation, which is off by 7.4 to $23.7 \%$. Lastly, when Model 4 of both SVM and ELM models is compared to the TSR-based Turc equation which is the best performing empirical model for this study, a significant improvement can still be observed, as there is an average increase in RRMSE of $57.5 \%$ or $0.2 \mathrm{~mm} /$ day, and in MAE of $58.2 \%$ or $0.17 \mathrm{~mm} /$ day. The estimates of Model 4 are off by only 2.4 to $8.2 \%$, while the Turc estimate is off by 7.1 to $12.5 \%$. The results show the ability of machine learning models to handle complex nonlinear relationships between independent variables and dependent variables when estimating daily ETo [23,32].

\subsection{Comparison of the Average Monthly ETo: The Case of UPLB and Tanay Stations}

The plots of the monthly average values, computed via the simulated daily ETo for all empirical and machine learning models, are shown in Figures 3 and 4 for the UPLB and Tanay stations, respectively. Among the studied empirical models, the average monthly daily estimates of the Turc equation excellently resemble the FAO-56 PM for the UPLB station (RMSE of $0.129 \mathrm{MJ} / \mathrm{m}^{2} /$ day and NSE of 0.969 ). In the case of the Tanay station, the Makkink equation performed best (RMSE of $0.216 \mathrm{MJ} / \mathrm{m}^{2} /$ day and NSE of 0.869 ). For both stations, the average monthly daily ETo computed via the Matt-Shuttleworth equation tended to be below the FAO-56 PM ETo, while the Priestley-Taylor equation overshot it. The T-based Hargreaves equation tended to overestimate the FAO-56 PM monthly and 
daily average ETo for the Tanay station throughout the whole year, but it only did so during the rainy seasons (JJA and SON) at the UPLB stations.

(a)
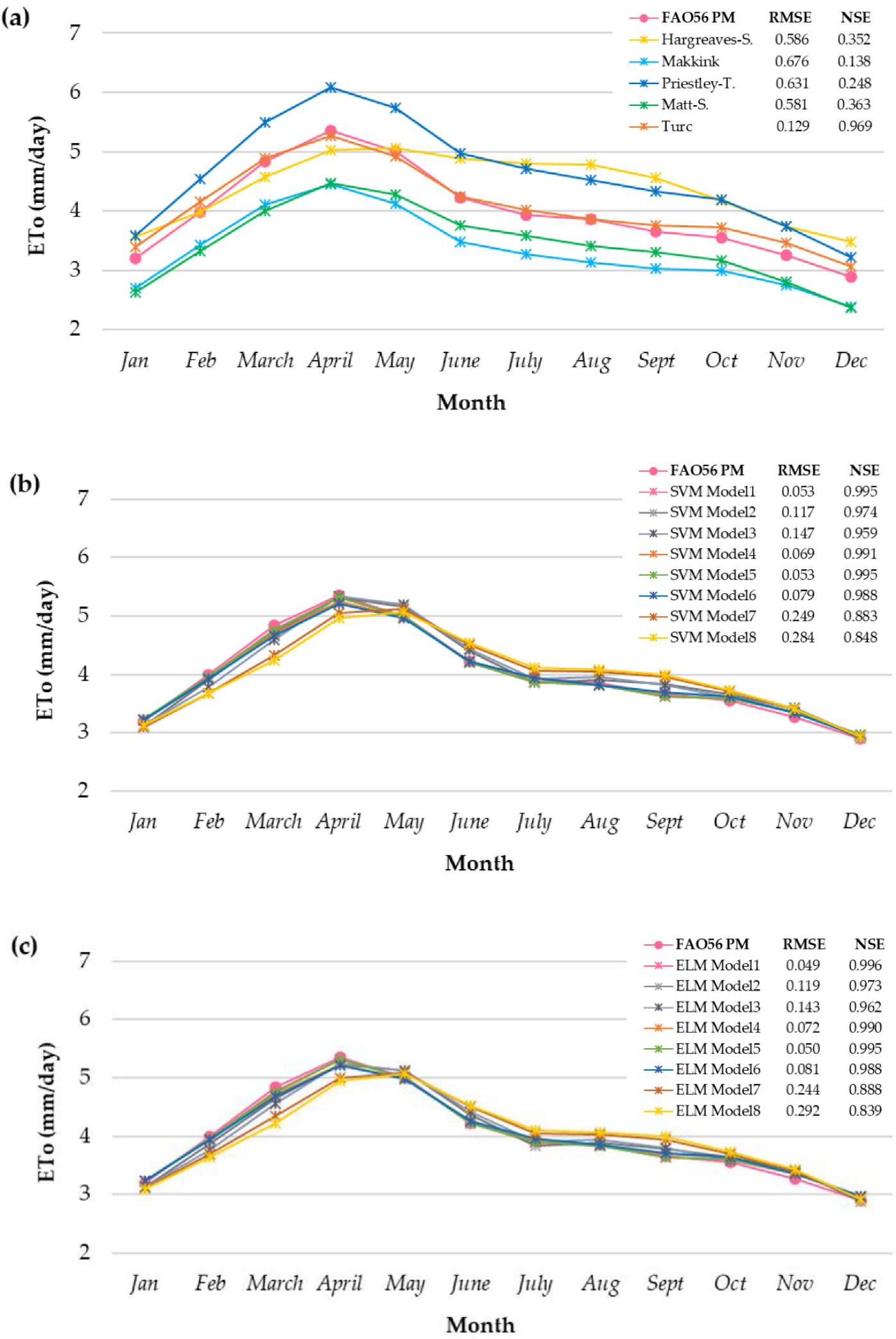

Figure 3. Plots of monthly average daily ETo at the UPLB station estimated from (a) empirical equations, and calibrated machine learning models of (b) Support Vector Machine and (c) Extreme Learning Machine. 
(a)
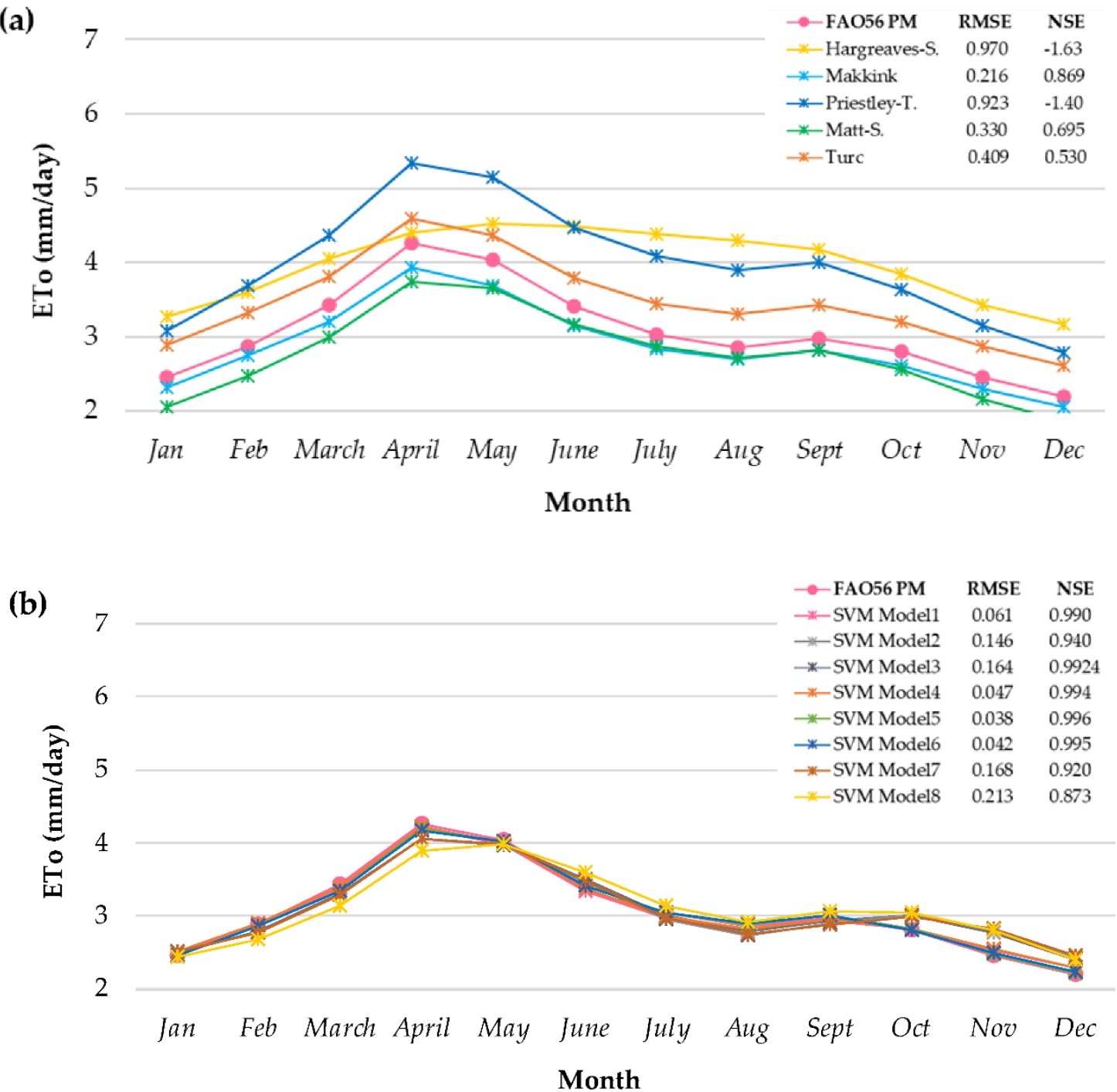

(c)

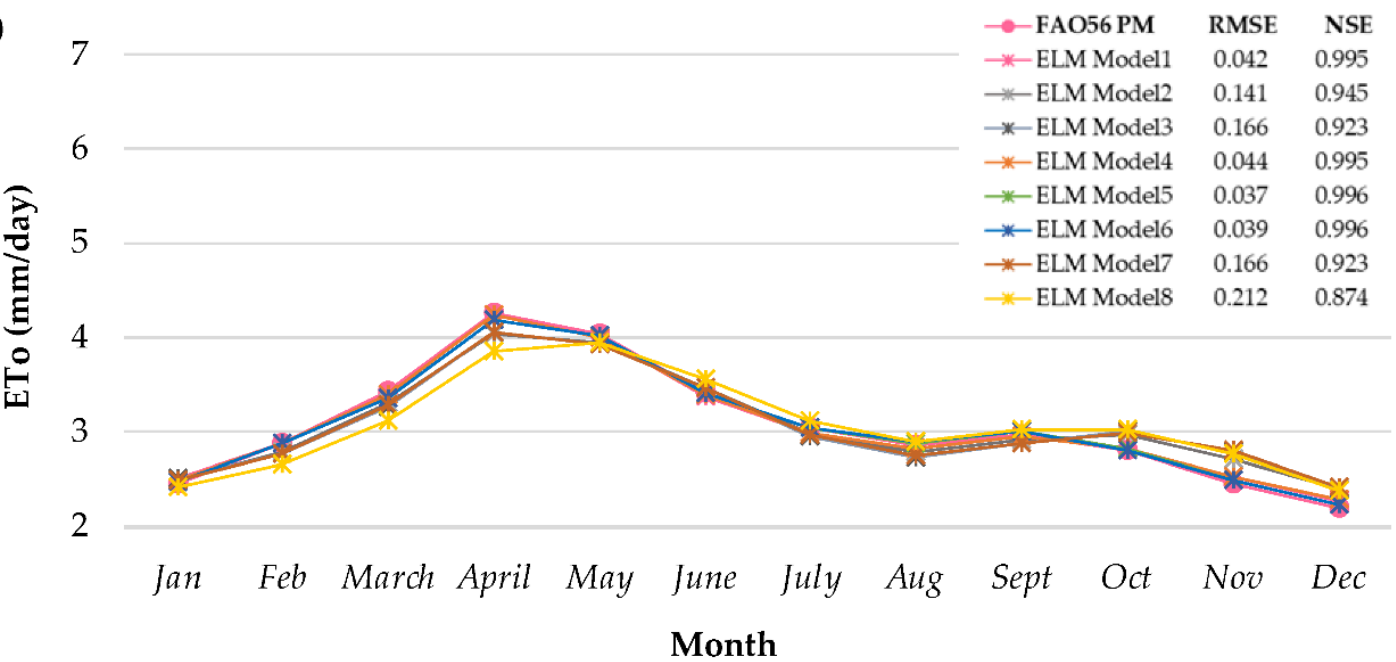

Figure 4. Plots of monthly average daily ETo at the Tanay station, estimated from (a) Empirical equations, and calibrated machine learning models of (b) Support Vector Machine and (c) Extreme Learning Machine. 
The average monthly ETo based on daily values computed via the SVM and ELM models, with any input combinations, proved to have a relatively high level of accuracy with NSE $>0.8$, which showed a closely reflected behavior of the monthly values based on FAO56-PM daily ETo. This proves that even with minimum inputs of air temperature data (Model 8), machine learning models can reliably and satisfactorily estimate ETo on a daily, monthly, and seasonal basis. The daily record of ETo is important in irrigation scheduling and hydrologic modeling, while monthly or seasonal estimates are necessary baseline data for irrigation system and reservoir designs, as well as water right determination [3].

\section{Conclusions}

Reliable data are key to forming good hydrological models and engineering designs. In particular, accurate estimates of ETo are important in irrigation planning and design, irrigation scheduling, reservoir management among other applications. This study developed models based on SVM with an RBF non-linear kernel function, and on ELM, for estimating daily reference crop evapotranspiration in Region IV-A, Philippines, using limited meteorological input data. The machine learning models developed were compared with five other established empirical models in terms of accuracy in daily ETo estimation. The results show that the calibrated SVM and ELM models, with at least $T_{\max }, T_{\min }$ and $R_{S}$ as inputs, provide the best daily ETo estimates. When compared to empirical models with analogous data inputs, the ELM and SVM models achieved higher accuracies, with RMSE values of at least $0.2 \mathrm{~mm} /$ day, and MAE values of $0.17 \mathrm{~mm} /$ day. Overall, the ELM and SVM models achieved similar modeling performances, although the former exhibited shorter run times than the latter. These machine learning models, with proper simulations and optimization, could achieve excellent performance in terms of accuracy.

Author Contributions: A.T.T.J. and V.B.E. developed the concept and methodology. A.T.T.J. performed model simulation from the model development and evaluation and wrote the initial draft. V.B.E., R.M.L. and C.E.R. improved the content and structure of the final paper. All authors have read and agreed to the published version of the manuscript.

Funding: This research was carried out with the support of Department of Science and TechnologyEngineering Research and Development Technology (DOST-ERDT) scholarship of the corresponding author and the Commission on Higher Education-Philippine-California Research Institutes (CHED-PCARI).

Data Availability Statement: Restrictions apply to the availability of the ground-based datasets. Data obtained from the DOST-PAGASA Central Station and the National Solar Radiation Center were requested through the online platform ClimaDatPh, while datasets from DOST-ASTI and DABSWM are available upon request from the agency (Retamar, A.E., et al. (2021). Meteorological Data Acquisition Stations for Information Dissemination (PCT/PH2021/050022)). NASA Power Rs data are available and can be accessed here: https:/ / power.larc.nasa.gov/data-access-viewer/. (Last accessed: 17 January 2022).

Acknowledgments: This study was supported by the DOST-ERDT and by the CHED-PCARI WiSEIr Project. The authors would like to thank the DOST-PAGASA, DOST-ASTI, DA-BSWM and NASAPOWER for providing the data used in this study.

Conflicts of Interest: The authors declare no conflict of interest.

\section{References}

1. Allen, R.G.; Pereira, L.S.; Raes, D.; Smith, M. FAO Irrigation and Drainage Paper No. 56 Crop Evapotranspiration (Guidelines for Computing Crop Water Requirements); Food and Agriculture Organization (FAO): Rome, Italy, 1998.

2. Pereira, L.S.; Allen, R.G.; Smith, M.; Raes, D. Crop evapotranspiration estimation with FAO56: Past and future. Agric. Water Manag. 2015, 147, 4-20. [CrossRef]

3. UPLB-AMTEC. PAES 217: Determination of Irrigation Water Requirements; University of the Philippines Los Banos-Agricultural Machinery Testing and Evaluation Center: Los Baños, Philippines, 2017; ISBN 6506035.

4. Ghiat, I.; Mackey, H.R.; Al-Ansari, T. A review of evapotranspiration measurement models, techniques and methods for open and closed agricultural field applications. Water 2021, 13, 2523. [CrossRef] 
5. Ella, V.B. Simple hydrologic model for predicting streamflow in small watersheds for irrigation system planning. Int. Agric. Eng. J. 2016, 25, 1-13.

6. Ricard, S.; Sylvain, J.D.; Anctil, F. Asynchronous Hydroclimatic Modeling for the Construction of Physically Based Streamflow Projections in a Context of Observation Scarcity. Front. Earth Sci. 2020, 8, 556781. [CrossRef]

7. Birhanu, D.; Kim, H.; Jang, C.; Park, S. Does the complexity of evapotranspiration and hydrological models enhance robustness? Sustainability 2018, 10, 2837. [CrossRef]

8. Mendicino, G.; Senatore, A. The Role of Evapotranspiration in the Framework of Water Resource Management and Planning Under Shortage Conditions. In Evapotranspiration—Remote Sensing and Modeling; Irmak, A., Ed.; InTech: Rijeka, Croatia, 2012; ISBN 978-953-307-808-3. [CrossRef]

9. Zamora, D.; Rodríguez, E.; Jaramillo, F. Hydroclimatic effects of a hydropower reservoir in a tropical hydrological basin. Sustainability 2020, 12, 6795. [CrossRef]

10. Ella, V.B. Simulating the Hydraulic Effects of Climate Change on Groundwater Resources in a Selected Aquifer in the Philippines Using a Numerical Groundwater Model; SEARCA: Los Baños, Philippines, 2011; ISBN 9788420548470.

11. Liu, W.; Yang, L.; Zhu, M.; Adamowski, J.F.; Barzegar, R.; Wen, X.; Yin, Z. Effect of elevation on variation in reference evapotranspiration under climate change in northwest china. Sustainability 2021, 13, 151. [CrossRef]

12. $\mathrm{Mu}, \mathrm{X}$.; Wang, H.; Zhao, Y.; Liu, H.; He, G.; Li, J. Streamflow into Beijing and its response to climate change and human activities over the period 1956-2016. Water 2020, 12, 622. [CrossRef]

13. Vicente-Serrano, S.M.; Beguería, S.; López-Moreno, J.I. A multiscalar drought index sensitive to global warming: The standardized precipitation evapotranspiration index. J. Clim. 2010, 23, 1696-1718. [CrossRef]

14. Tian, L.; Leasor, Z.T.; Quiring, S.M. Developing a hybrid drought index: Precipitation Evapotranspiration Difference Condition Index. Clim. Risk Manag. 2020, 29, 100238. [CrossRef]

15. Mehdizadeh, S.; Mohammadi, B.; Pham, Q.B.; Duan, Z. Development of boosted machine learning models for estimating daily reference evapotranspiration and comparison with empirical approaches. Water 2021, 13, 3489. [CrossRef]

16. Peng, L.; Li, Y.; Feng, H. The best alternative for estimating reference crop evapotranspiration in different sub-regions of mainland China. Sci. Rep. 2017, 7, 5458. [CrossRef] [PubMed]

17. Hargreaves, G.; Samani, Z. Reference crop evapotranspiration from ambient air temperature. Am. Soc. Agric. Eng. 1985, 1, 96-99. [CrossRef]

18. De Bruin, H. The determination of (reference crop) evapotranspiration from routine weather data. Comm. Hydrol. Res. 1981, 28, 25-37.

19. Priestley, C.; Taylor, R. On the assessment of surface heat flux and evaporation using large-scale parameters. Mon. Weather Rev. 1972, 100, 81-92. [CrossRef]

20. Shuttleworth, W.; Wallace, J. Calculating the water requirements of irrigated crops in Australia using the Matt-Shuttleworth approach. Trans. ASABE 2009, 52, 1895-1906. [CrossRef]

21. Turc, L. Estimation of irrigation water requirements, potential evapotranspiration: A simple climatic formula evolved up to date. Ann. Agron. 1961, 12, 13-49.

22. Chia, M.Y.; Huang, Y.F.; Koo, C.H. Support vector machine enhanced empirical reference evapotranspiration estimation with limited meteorological parameters. Comput. Electron. Agric. 2020, 175, 105577. [CrossRef]

23. Ferreira, L.B.; da Cunha, F.F.; de Oliveira, R.A.; Fernandes Filho, E.I. Estimation of reference evapotranspiration in Brazil with limited meteorological data using ANN and SVM-A new approach. J. Hydrol. 2019, 572, 556-570. [CrossRef]

24. Seifi, A.; Riahi, H. Estimating daily reference evapotranspiration using hybrid gamma test-least square support vector machine, gamma test-ann, and gamma test-anfis models in an arid area of iran. J. Water Clim. Chang. 2020, 11, 217-240. [CrossRef]

25. Torres, A.F.; Walker, W.R.; McKee, M. Forecasting daily potential evapotranspiration using machine learning and limited climatic data. Agric. Water Manag. 2011, 98, 553-562. [CrossRef]

26. Samuel, A.L. Some Studies in Machine Learning. IBM J. Res. Dev. 1959, 3, 210-229. [CrossRef]

27. Subasi, A. Practical Machine Learning for Data Analysis Using Python; Elsevier: London, UK, 2020; ISBN 9780128213797. [CrossRef]

28. Feng, Y.; Cui, N.; Zhao, L.; Hu, X.; Gong, D. Comparison of ELM, GANN, WNN and empirical models for estimating reference evapotranspiration in humid region of Southwest China. J. Hydrol. 2016, 536, 376-383. [CrossRef]

29. Gocic, M.; Petković, D.; Shamshirband, S.; Kamsin, A. Comparative analysis of reference evapotranspiration equations modelling by extreme learning machine. Comput. Electron. Agric. 2016, 127, 56-63. [CrossRef]

30. Ehteram, M.; Singh, V.P.; Ferdowsi, A.; Mousavi, S.F.; Farzin, S.; Karami, H.; Mohd, N.S.; Afan, H.A.; Lai, S.H.; Kisi, O.; et al. An improved model based on the support vector machine and cuckoo algorithm for simulating reference evapotranspiration. PLoS ONE 2019, 14, e0217499. [CrossRef] [PubMed]

31. Kumar, D.; Adamowski, J.; Suresh, R.; Ozga-Zielinski, B. Estimating Evapotranspiration Using an Extreme Learning Machine Model: Case Study in North Bihar, India. J. Irrig. Drain. Eng. 2016, 142, 04016032. [CrossRef]

32. Fan, J.; Yue, W.; Wu, L.; Zhang, F.; Cai, H.; Wang, X.; Lu, X.; Xiang, Y. Evaluation of SVM, ELM and four tree-based ensemble models for predicting daily reference evapotranspiration using limited meteorological data in different climates of China. Agric. For. Meteorol. 2018, 263, 225-241. [CrossRef] 
33. Yin, Z.; Feng, Q.; Yang, L.; Deo, R.C.; Wen, X.; Si, J.; Xiao, S. Future projection with an extreme-learning machine and support vector regression of reference evapotranspiration in a mountainous inland watershed in north-west China. Water 2017, 9, 880. [CrossRef]

34. Bellido-Jiménez, J.A.; Estévez, J.; García-Marín, A.P. New machine learning approaches to improve reference evapotranspiration estimates using intra-daily temperature-based variables in a semi-arid region of Spain. Agric. Water Manag. 2021, $245,106558$. [CrossRef]

35. Wu, J.; Chen, X.Y.; Zhang, H.; Xiong, L.D.; Lei, H.; Deng, S.H. Hyperparameter optimization for machine learning models based on Bayesian optimization. J. Electron. Sci. Technol. 2019, 17, 26-40. [CrossRef]

36. Syarif, I.; Prugel-Bennett, A.; Wills, G. SVM Parameter Optimization using Grid Search and Genetic Algorithm to Improve Classification Performance. TELKOMNIKA Telecommun. Comput. Electron. Control. 2016, 14, 1502. [CrossRef]

37. Wainer, J.; Cawley, G. Empirical evaluation of resampling procedures for optimising SVM hyperparameters. J. Mach. Learn. Res. 2017, 18, 1-35.

38. Patil, A.P.; Deka, P.C. An extreme learning machine approach for modeling evapotranspiration using extrinsic inputs. Comput. Electron. Agric. 2016, 121, 385-392. [CrossRef]

39. Wen, X.; Si, J.; He, Z.; Wu, J.; Shao, H.; Yu, H. Support-Vector-Machine-Based Models for Modeling Daily Reference Evapotranspiration With Limited Climatic Data in Extreme Arid Regions. Water Resour. Manag. 2015, 29, 3195-3209. [CrossRef]

40. FAO. Information and Communication Technology (ICT) in Agriculture: A Report to the G20 Agricultural Deputies; FAO: Rome, Italy, 2017; Volume 22.

41. World Bank Group Future of Food. Harnessing Digital Technologies to Improve Food Systems Outcome; World Bank Group Future of Food: Washington, DC, USA, 2019.

42. Benos, L.; Tagarakis, A.C.; Dolias, G.; Berruto, R.; Kateris, D.; Bochtis, D. Machine learning in agriculture: A comprehensive updated review. Sensors 2021, 21, 3758. [CrossRef]

43. Mehrabi, Z.; McDowell, M.J.; Ricciardi, V.; Levers, C.; Martinez, J.D.; Mehrabi, N.; Wittman, H.; Ramankutty, N.; Jarvis, A. The global divide in data-driven farming. Nat. Sustain. 2021, 4, 154-160. [CrossRef]

44. Grossman, D.; Doyle, M.; Buckley, N. Data Intelligence for 21st Century Water Management; The Aspen Institute: Washington, DC, USA, 2015; ISBN 0898436311.

45. Liakos, K.G.; Busato, P.; Moshou, D.; Pearson, S. Machine Learning in Agriculture: A Review. Sensor 2018, 18, 2674. [CrossRef]

46. Villafuerte, M.I.Q.; Lambrento, J.C.R.; Ison, C.M.S.; Vicente, A.A.S.; de Guzman, R.G.; Juanillo, E.L. ClimDatPh: An Online Platform for Philippine Climate Data Acquisition. Philipp. J. Sci. 2021, 150, 53-66.

47. Tejada, A.T., Jr.; Ella, V.B.; Lampayan, R.M.; Reano, C.E. Assessment of the Accuracy of NASA-POWER Reanalysis Dataset for Estimating Daily Solar Radiation in Region IV-A, Philippines. In Proceedings of the 2021 Virtual ISSAAS National Scientific Congress, Los Baños, Philippines, 16-17 December 2021.

48. Bai, J.; Chen, X.; Dobermann, A.; Yang, H.; Cassman, K.G.; Zhang, F. Evaluation of nasa satellite-and model-derived weather data for simulation of maize yield potential in China. Agron. J. 2010, 102, 9-16. [CrossRef]

49. Negm, A.; Jabro, J.; Provenzano, G. Agricultural and Forest Meteorology Assessing the suitability of American National Aeronautics and Space Administration (NASA) agro-climatology archive to predict daily meteorological variables and reference evapotranspiration in Sicily, Italy. Agric. For. Meteorol. 2017, 244-245, 111-121. [CrossRef]

50. Sayago, S.; Ovando, G.; Almorox, J.; Bocco, M. Daily solar radiation from NASA-POWER product: Assessing its accuracy considering atmospheric transparency Daily solar radiation from NASA-POWER product: Assessing. Int. J. Remote Sens. 2019, 41, 897-910. [CrossRef]

51. White, J.W.; Hoogenboom, G.; Wilkens, P.W.; Stackhouse, P.W.; Hoel, J.M. Evaluation of satellite-based, modeled-derived daily solar radiation data for the continental United States. Agron. J. 2011, 103, 1242-1251. [CrossRef]

52. Guo, D.; Westra, S.; Maier, H.R. An R package for modelling actual, potential and reference evapotranspiration. Environ. Model. Softw. 2016, 78, 216-224. [CrossRef]

53. Vapnik, V.N. The Nature of Statistical Learning Theory; Springer: New York, NY, USA, 2000; ISBN 0-387-98780-0.

54. Rhys, H. Machine Learning with R, the Tidyverse, and Mlr; Manning Publications: New York, NY, USA, 2020.

55. Shekar, B.H.; Dagnew, G. Grid search-based hyperparameter tuning and classification of microarray cancer data. In Proceedings of the International Conference on Advanced Computational and Communication Paradigms (ICACCP), Gangtok, India, 25-28 February 2019; pp. 1-8. [CrossRef]

56. Huang, G.B.; Zhu, Q.Y.; Siew, C.K. Extreme learning machine: Theory and applications. Neurocomputing 2006, 70, $489-501$. [CrossRef]

57. Fan, J.; Wang, X.; Wu, L.; Zhang, F.; Bai, H.; Lu, X. New combined models for estimating daily global solar radiation based on sunshine duration in humid regions: A case study in South China. Energy Convers. Manag. 2018, 156, 618-625. [CrossRef]

58. Zhang, J.; Xu, Y.; Xue, J.; Xiao, W. Real-time prediction of solar radiation based on online sequential extreme learning machine. In Proceedings of the IEEE Conference on Industrial Electronics and Applications (ICIEA), Wuhan, China, 31 May-2 June 2018; pp. 53-57. [CrossRef]

59. Hyndman, R.J.; Athanasopoulos, G. Forecasting: Principles and Practice, 2nd ed.; OTexts: Melbourne, Australia, 2013; Available online: https:/ / otexts.com/fpp2 (accessed on 17 January 2022). 
60. Schnaubelt, M. A Comparison of Machine Learning MODEL Validation Schemes for Non-Stationary Time Series Data; FriedrichAlexander-Universität Erlangen-Nürnberg, Institute for Economics: Nürnberg, Germany, 2019.

61. Varma, S.; Simon, R. Bias in error estimation when using cross-validation for model selection. BMC Bioinform. 2006, 7, 91. [CrossRef]

62. Despotovic, M.; Nedic, V.; Despotovic, D.; Cvetanovic, S. Review and statistical analysis of different global solar radiation sunshine models. Renew. Sustain. Energy Rev. 2015, 52, 1869-1880. [CrossRef] 